\title{
Z-scheme CdS/BiVO4 Photocatalyst for Highly Efficient Photodegradation of Organic Pollutants and DFT Calculation
}

\section{Lianwei Shan}

Harbin University of Science and Technology

\section{Mingqi Yuan}

Harbin University of Science and Technology

Chengguo Ma ( $\mathbf{0 8 5 2 8 3 6 7 @ 1 6 3 . c o m ) ~}$

Harbin University of Science and Technology https://orcid.org/0000-0002-4673-5374

Changhui Lu

Harbin University of Science and Technology

\section{Zilan Fang}

Harbin University of Science and Technology

Shuituan Lin

Harbin University of Science and Technology

Dan Li

Harbin University of Science and Technology

\section{Ze Wu}

Harbin University of Science and Technology

Limin Dong

Harbin University of Science and Technology

\section{Guolin Qian}

Suzhou Vocational University

\section{Lixin Yang}

Chinese Academy of Sciences

\section{Research Article}

Keywords: Photocatalyst, Electrophoretic deposition, DFT, Z-scheme, CdS/BiVO4, Heterostructure

Posted Date: April 1st, 2021

DOl: https://doi.org/10.21203/rs.3.rs-373821/v1 
License: (c) (i) This work is licensed under a Creative Commons Attribution 4.0 International License. Read Full License 


\title{
Z-scheme $\mathrm{CdS} / \mathrm{BiVO}_{4}$ photocatalyst for highly efficient photodegradation of organic pollutants and DFT calculation
}

\author{
Lianwei Shan ${ }^{1}$, Mingqi Yuan ${ }^{1}$, Chengguo Ma ${ }^{1 *}$, Changhui Lu ${ }^{1}$, Zilan Fang ${ }^{1}$, shuituan Lin $^{1}$, Dan Li ${ }^{1}, Z e$ Wu$^{1}$, Limin Dong $^{1 *}$, Guolin \\ Qian $^{2}$, Lixin Yang ${ }^{3}$ \\ ${ }^{1}$ School of Materials Science and Engineering, Harbin University of Science and Technology, Harbin 150040, China \\ ${ }^{2}$ College of Electronic Information Engineering\& Engineering Research and Development Center for Photovoltaic Technology of \\ Jiangsu Province, Suzhou Vocational University, Suzhou 215106, China \\ ${ }^{3}$ Shenyang National Laboratory for Materials Science, Institute of Metal Research, Chinese Academy of Sciences, Wenhua Road 72 , \\ 110016 Shenyang, China \\ Corresponding authors(88528367@163.com;donglimin@hrbust.edu.cn)
}

\begin{abstract}
In the field of photocatalysis, the heterojunction strategy is one of the effective ways to settle the problems of rapid recombination and sluggish mobility of the photo-generated carriers. Herein, we used a strategy of electrophoretic deposition to synthesize Z-scheme $\mathrm{CdS} / \mathrm{BiVO}_{4}$. Interestingly, compared with the pristine $\mathrm{CdS}$ and $\mathrm{BiVO}_{4}$, the prepared $\mathrm{CdS} / \mathrm{BiVO}_{4}$ showed effective charge separation, high degradation efficiency and well photocatalytic stability. It demonstrated that electrophoretic deposition can successfully construct photocatalyst steadily and effectively heterostructured $\mathrm{CdS} / \mathrm{BiVO}_{4}$. Meanwhile, the electron transfer paths between $\mathrm{BiVO}_{4}$ and $\mathrm{CdS}$ were probed by the DFT calculations. We infer that there is a Z-scheme mechanism between $\mathrm{BiVO}_{4}$ and $\mathrm{CdS}$. Moreover, this efficient strategy can support more applications for more efficient composition design of semiconductor heterojunctions.
\end{abstract}

KEYWORDS: Photocatalyst, Electrophoretic deposition, DFT, Z-scheme, CdS/BiVO 4 , Heterostructure

\section{Introduction}

Environmental pollution and energy crisis have brought about considerable attentions to the researchers in recent years. Photocatalysis provides a feasible strategy for alleviating above issues due to potential applications in degrading organic pollutants and photocatalytic water splitting [1-4]. However, the wide band gap, the rapid recombination of the photo-generated carriers and fewer surface active sites result in that the photocatalytic abilities of semiconductor photocatalysts were limited [5-8]. Consequently, to obtain the efficient and stable photocatalysts, the rationalized regulating strategy is crucial.

Up to now, various regulating strategies have been reported various strategies such as doping [9-11], surface modification [12,13], construction of heterostructure [14-16] and homojunction [17] etc. Among the methods mentioned above, the construction of heterojunction will lead to the alignment of the Fermi level of the semiconductor photocatalysts and thereby generate the interfacial electric field, which would effectively facilitate the separation of photo-generated carriers [18]. And the direct Z-scheme heterostructure is ascribed to the reduction and oxidation potential of the photocatalyst be optimized and the promotion of the spatial transfer of photo-generated carriers, and become a hot topic in the field of heterojunction [19]. Despite composite photocatalysts have revealed many advantages, most approaches in preparing composite photocatalysts exist some limitations to some extent. P. Joice Sophia et al. synthesized $\mathrm{CdS} / \mathrm{Ag}_{2} \mathrm{O}$ nanocomposites by chemical precipitation method [20]. In this method, the excessive $\mathrm{NaOH}$ was added in the preparation process to generate $\mathrm{Ag}_{2} \mathrm{O}$, which will lead to multiple subsequent cleaning, and the generated flocculent precipitation needed to be dried at $160{ }^{\circ} \mathrm{C}$. $\mathrm{He}$ et al. synthesized $\mathrm{BiOCl} / \mathrm{BiVO}_{4}$ heterostructures through a hydrothermal process of keeping at $180{ }^{\circ} \mathrm{C}$ for $10 \mathrm{~h}$

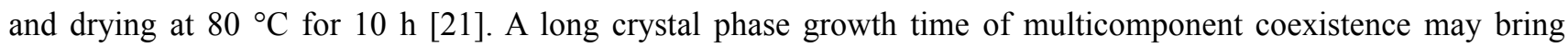


about the impurity and high product cost. Also more uncontrollable factors and high cost in the process of utilizing traditional methods to synthesize the composite photocatalyst are not suitable for the industrial production [22].

In recent years, numerous works have been concentrated on $\mathrm{CdS}$ and $\mathrm{BiVO}_{4}$ because of their suitable band gap and immense potential application in photocatalysis $[23,24]$. As a type II-VI direct band gap semiconductor, CdS has been widely employed in light harvesting and photocatalytic experiments due to its suitable valence band position, narrow band gap (about $2.40 \mathrm{eV}$ ) and high extinction coefficient [25-27]. When the wavelength of the incident sunlight is less than $495 \mathrm{~nm}$, the valence band electrons of CdS are easily excited to enter the conduction band $[28,29]$. We know, monoclinic scheelite $\mathrm{BiVO}_{4}$ has revealed superior photocatalytic activities over the other phases because of the narrow band gap (about $2.4 \mathrm{eV}$ ) [30,31], low toxicity, abundant sources and well stability [32]. Nevertheless, $\mathrm{CdS}$ is more prone to agglomeration during the photocatalysis process, which obviously leads to decrease in surface area and it is difficult to restrain the recombination of photo-generated carriers [33,34]. Consequently, to improve the photocatalytic activity of CdS, it is crucial to seek a convenient and effective approach to form an efficient photocatalyst.

Herein, we proposed a strategy to prepare the photocatalysts of $\mathrm{Z}$-scheme $\mathrm{CdS} / \mathrm{BiVO}_{4}$ with different ratios by controlled electrophoretic deposition method. This physical approach to prepare semiconductor photocatalyst can not only enhance the preparation efficiency and reduce energy consumption, but also there is no need to further purify and dry. The photocatalytic performances of $\mathrm{CdS} / \mathrm{BiVO}_{4}$ were evaluated by photodegradation of rhodamine $\mathrm{B}(\mathrm{RhB})$ and methyl orange (MO). Essentially, this physical combining approach is to form electrostatic attraction of interfaces between $\mathrm{CdS}$ and $\mathrm{BiVO}_{4}$, which reasonably construct Z-scheme heterostructure. The transfer mechanism of electrons between $\mathrm{BiVO}_{4}$ and CdS was investigated by density functional theory (DFT) calculations. We infer that the formation of a Z-scheme heterostructure between $\mathrm{BiVO}_{4}$ and $\mathrm{CdS}$ realizes the interface effect. Thus, the synthesized Z-scheme $\mathrm{CdS} / \mathrm{BiVO}_{4}$ displayed higher efficient photocatalytic activity and stability compared with the pristine $\mathrm{CdS}$ and $\mathrm{BiVO}_{4}$.

\section{Experimental Section}

\subsection{Preparation}

All chemicals were reagent grade and used without purification. The traditional hydrothermal method is utilized to prepare $\mathrm{BiVO}_{4}$ particles: firstly, $2.5 \mathrm{mmol}$ of $\mathrm{Bi}\left(\mathrm{NO}_{3}\right)_{3} \cdot 5 \mathrm{H}_{2} \mathrm{O}$ was dissolved in $5 \mathrm{~mL}$ of $1 \mathrm{M} \mathrm{HNO}_{3}$, and magnetically stirred for 30 minutes to obtain a colorless solution A. Then, $2.5 \mathrm{mmol}$ of $\mathrm{NH}_{4} \mathrm{VO}_{3}$ was dissolved in 2 $\mathrm{M} \mathrm{NaOH}$ solution, and after magnetic stirring of half hour the clarified solution B was obtained. Subsequently, solution B was added dropwise to solution A to acquire a yellow mixed suspension, and then the $\mathrm{pH}$ was adjusted to 7 with $2 \mathrm{M} \mathrm{NaOH}$ solution. Ultimately, the mixed suspension was transferred and sealed in a $100 \mathrm{~mL}$ Teflon-lined autoclave, heated to $180^{\circ} \mathrm{C}$ and maintained for $12 \mathrm{~h}$. The yellow precipitate obtained was collected by centrifugation and washing, and then dried in air at $80^{\circ} \mathrm{C}$.

CdS nanoparticles were prepared by a water bath method. Firstly, 5 mmol sodium citrate was dissolved in $50 \mathrm{~mL}$ deionized water, and magnetically stirred for $2 \mathrm{~h}$ to obtain a transparent solution. Thereafter, $10 \mathrm{~mL}$ of $\mathrm{CdCl}_{2}(0.3$ mol L-1) solution was slowly added into the above transparent solution and magnetically stirred for $20 \mathrm{~min}$. Thirdly, $5 \mathrm{~mL} \mathrm{NH}_{3} \cdot \mathrm{H}_{2} \mathrm{O}(28 \mathrm{wt} \%)$ and $10 \mathrm{~mL} 0.9 \mathrm{M}$ thiourea $\left(\mathrm{CH}_{4} \mathrm{~N}_{2} \mathrm{~S}\right)$ solution were slowly added into the above mixed solution, respectively. The mixed solution was maintained in a $60{ }^{\circ} \mathrm{C}$ water bath for $3 \mathrm{~h}$. The yellow precipitate was collected by centrifugation, then washed thoroughly with ethanol and deionized water, and then dried in the air at $80^{\circ} \mathrm{C}$ to obtain the product $\mathrm{CdS}$.

$\mathrm{CdS} / \mathrm{BiVO}_{4}$ composites were obtained by depositing pure $\mathrm{BiVO}_{4}$ and $\mathrm{CdS}$ powder samples onto $\mathrm{FTO}$ substrate by electrophoretic deposition. In a typical preparation, firstly, $0.05 \mathrm{~g} \mathrm{CdS}, 0.112 \mathrm{~g} \mathrm{BiVO}_{4}$ and $0.005 \mathrm{~g} \mathrm{I}_{2}$ were ultrasonically dispersed in $20 \mathrm{~mL}$ acetone according to a molar ratio of $\mathrm{CdS}$ and $\mathrm{BiVO}_{4}$ is 1:1. Secondly, two clean 
FTO substrates were attached to the electrodes and inserted into the acetone solution. The conductive surfaces of the two FTO substrates were opposed to each other and kept at a distance of $1 \mathrm{~cm}$. Thirdly, turn on the DC voltage stabilizer and adjust the voltage to $25 \mathrm{~V}$. Under the action of the electric field, the $\mathrm{BiVO}_{4}$ and $\mathrm{CdS}$ were adsorbed on the FTO substrate. Formed uniform film was named as CV-4. The CV-x products with different ratios were prepared according to the molar ratio of $\mathrm{CdS}$ to $\mathrm{BiVO}_{4}$ are 1: $0.25,1: 0.5,1: 0.75$ (CV-1 CV-3), respectively. Although the proportions of the samples deposited are different, the total mass of the deposits is about $3 \mathrm{mg}$. Meanwhile, $3 \mathrm{mg}$ of pure $\mathrm{BiVO}_{4}$ and pure CdS were deposited on their respective FTO by electrophoretic deposition. The mechanism of CdS and $\mathrm{BiVO}_{4}$ electrophoretic deposition is demonstrated in Figure 1.

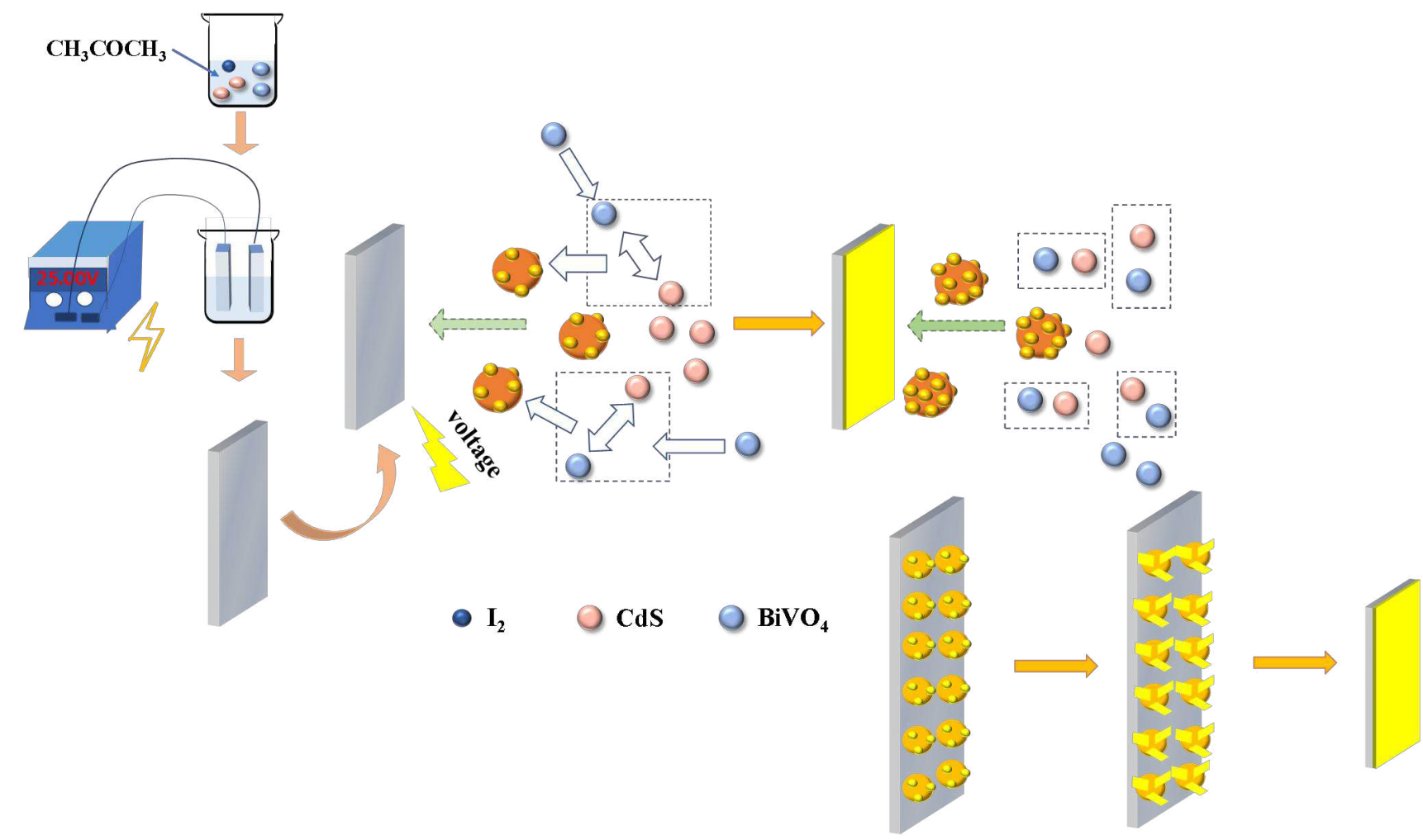

Figure 1. Formation mechanism of electrophoretic deposition of $\mathrm{CdS} / \mathrm{BiVO}_{4}$

Unlike traditional strategies of composite preparation, our electrophoretic deposition strategy can avoid the growth of the second crystalline phase, which significantly improves the preparation efficiency of high-efficiency photocatalysts [35].

\subsection{Characterization}

The phase structure of the crystalline material of the products was inspected by utilizing X-ray diffraction equipment (Model: X'Pert PRO MPD) with scanning rate of $0.02 \mathrm{~s}^{-1}$ and diffraction angle of $10-70^{\circ}$. Scanning electron microscope (SEM, FEISirion200) and energy dispersive spectrometer (EDS) were ubiquitously employed to characterize the morphology, grain size and element distribution of the products. The crystal size and structure were investigated by transmission electron microscopy (TEM, JEM2010). The photo-generated carriers recombination rate was detected by fluorescence spectrophotometer (Shimadzu, model RF-5301 PC) at the excitation wavelength of $340 \mathrm{~nm}$. Electrochemical impedance spectroscopy (EIS) and Mott-Schottky spectrum (M-S) were obtained by electrochemical workstation (VMP3). The three-electrode system consists of platinum foil electrode as the counter electrode and saturated calomel electrode as the reference electrode, and $0.5 \mathrm{M} \mathrm{Na}_{2} \mathrm{SO}_{4}$ as the electrolyte solution.

\subsection{Photocatalytic experiments}

The photocatalytic activities of the obtained products were carried out by degrading $\mathrm{MO}$ and $\mathrm{RhB}$ under visible 
light irradiation ( $300 \mathrm{~W}$ Xe lamp). The prepared $\mathrm{CdS}, \mathrm{BiVO}_{4}$ and $\mathrm{CV}-\mathrm{x}(\mathrm{x}=1 \sim 4)$ were put into $100 \mathrm{~mL}$ of $\mathrm{MO}(\mathrm{RhB})$ aqueous solution $\left(10 \mathrm{mg} \mathrm{L}^{-1}\right)$, respectively. In order to ensure the adsorption-desorption equilibrium, the above solutions were placed in the dark for $30 \mathrm{~min}$. Then under visible light irradiation, at a given time interval, we used a UV-Vis spectrophotometer (UV757CRT) to monitor the maximum absorption wavelength (460 nm or $554 \mathrm{~nm}$ ) for final the photodegradation efficiency. The light absorption of MO at $460 \mathrm{~nm}(\mathrm{RhB}$ at $554 \mathrm{~nm}$ ) was monitored for photodegradation process.

\subsection{Computational methods and details}

To determine the charge transfer between $\mathrm{CdS}$ and $\mathrm{BiVO}_{4}$, we carried out DFT calculations using the Vienna $\mathrm{Ab}$ initio Simulation Package (VASP) code [36,37]. Meanwhile, the generalized gradient approximation (GGA) of the Perdew-Burke-Ernzerhof (PBE) is adopted for the exchange and correlation potential [38]. According to previous report, the (010) facet of the $C 2 / c$ cell with monoclinic lattice constant exhibit approximate band gap, work function, and the lowest surface energy of the (001) facet of the $I 2 / b$ cell with tetragonal lattice constant [39]. Therefore, we refer to the (001) plane of $I 2 / b$ cell as the (010) facet. The (010) surface structure of $\mathrm{BiVO}_{4}$ contains 108 atoms, $8 \mathrm{Bi}$ layers and vacuum slab of $15 \AA$. It is cleaved from cell with tetragonal lattice parameters $(\mathrm{a} / \mathrm{b}=$ $5.215 \AA, c=11.706 \AA, \alpha / \beta / \gamma=90^{\circ}$ ) of $I 2 / b$. Meanwhile, the (100) surface structure of CdS contains 84 atoms, 13 Cd layers and vacuum slab of $15 \AA$, which is cleaved from cell of P63mc with hexagonal lattice constant. (010) and (100) surface properties are obtained from $6 \times 7 \times 1$ and $8 \times 5 \times 1$ k-point meshes, respectively.

\section{Results and discussion}

\subsection{Phase structure and composition}

The crystalline structures of $\mathrm{BiVO}_{4}, \mathrm{CdS}$ and CV-x $(\mathrm{x}=1 \sim 4)$ were investigated by X-ray diffraction (XRD) as depicted in Figure 2a. The diffraction peak of the pristine $\mathrm{CdS}$ and $\mathrm{BiVO}_{4}$ were detected, which are consistent with the standard CdS (ICSD, no. 41-1049; a / b $=4.141 \AA, c=6.720 \AA, \alpha / \beta=90^{\circ}, \gamma=120^{\circ}$ ) and $\mathrm{BiVO}_{4}$ (space group: I2/a, ICSD, no. 14-0688), demonstrating that the crystal phases of the obtained products was hexagonal phase and monoclinic phase, respectively [40]. In addition, the impurity peaks appeared should belong to the FTO (F doped $\mathrm{SnO}_{2}$ ). Figure $2 \mathrm{~b}$ shows partially enlarged views of $26.5^{\circ}$ in Figure $2 \mathrm{a}$. It could be distinctly discovered that the diffraction peak of CdS was continually weakened due to the continuous increase of $\mathrm{BiVO}_{4}$ content. Hence, the XRD results can illustrate that electrophoretic deposition can effectively regulate the ratio of composite photocatalysts.
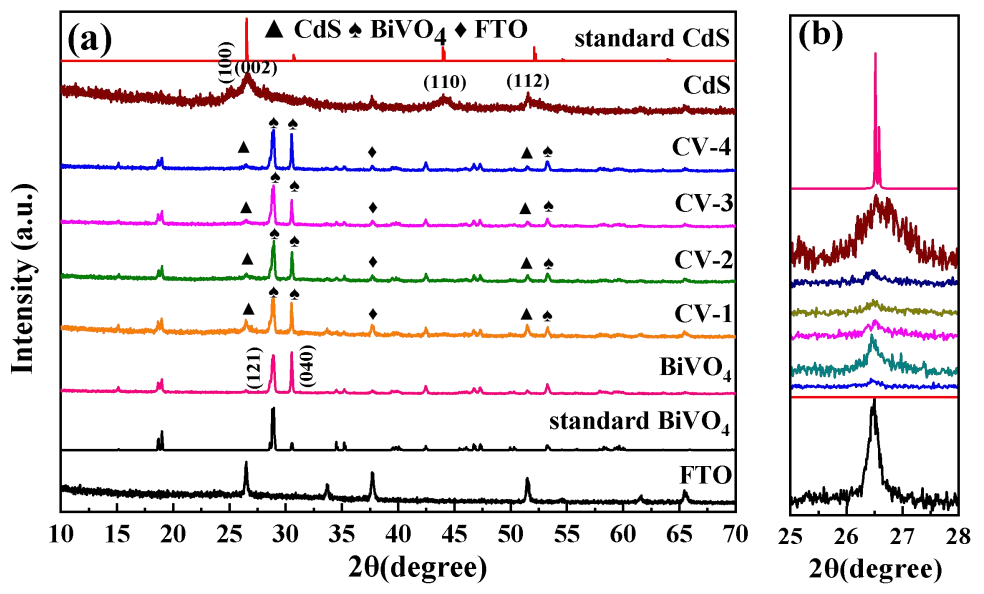

Figure 2. The XRD patterns of $\mathrm{BiVO}_{4}, \mathrm{CdS}, \mathrm{CV}-\mathrm{x}(\mathrm{x}=1 \sim 4)$ and FTO.

\subsection{Morphology and microstructure}

SEM was employed to investigate the morphology and elemental distribution of $\mathrm{CdS}, \mathrm{BiVO}_{4}$ and $\mathrm{CV}-3$ as portrayed in Figure 3. The microscopic morphology of the as-prepared $\mathrm{BiVO}_{4}$ was depicted in Figure 3a, 
observing irregular worm-like particles with the size of about $1 \sim 2 \mu \mathrm{m}$ [41]. As shown in Figure $3 \mathrm{~b}$, the CdS is characteristic of accumulating with numerous tiny nanoparticles. As described in Figure $3 \mathrm{c}$ and EDS, all elements ( $\mathrm{Bi}, \mathrm{V}, \mathrm{O}, \mathrm{Cd}, \mathrm{S}$ ) were detected in $\mathrm{CV}-3$, corresponding to $\mathrm{BiVO}_{4}$ and $\mathrm{CdS}$. Meanwhile, the $\mathrm{BiVO}_{4}$ particles were evenly surrounded by CdS nanoparticles in CV-3. Therefore, it can be inferred that electrophoretic deposition can successfully couple $\mathrm{CdS}$ and $\mathrm{BiVO}_{4}$ to form well-defined microscopic morphology, which is conducive to provide more reactive sites.
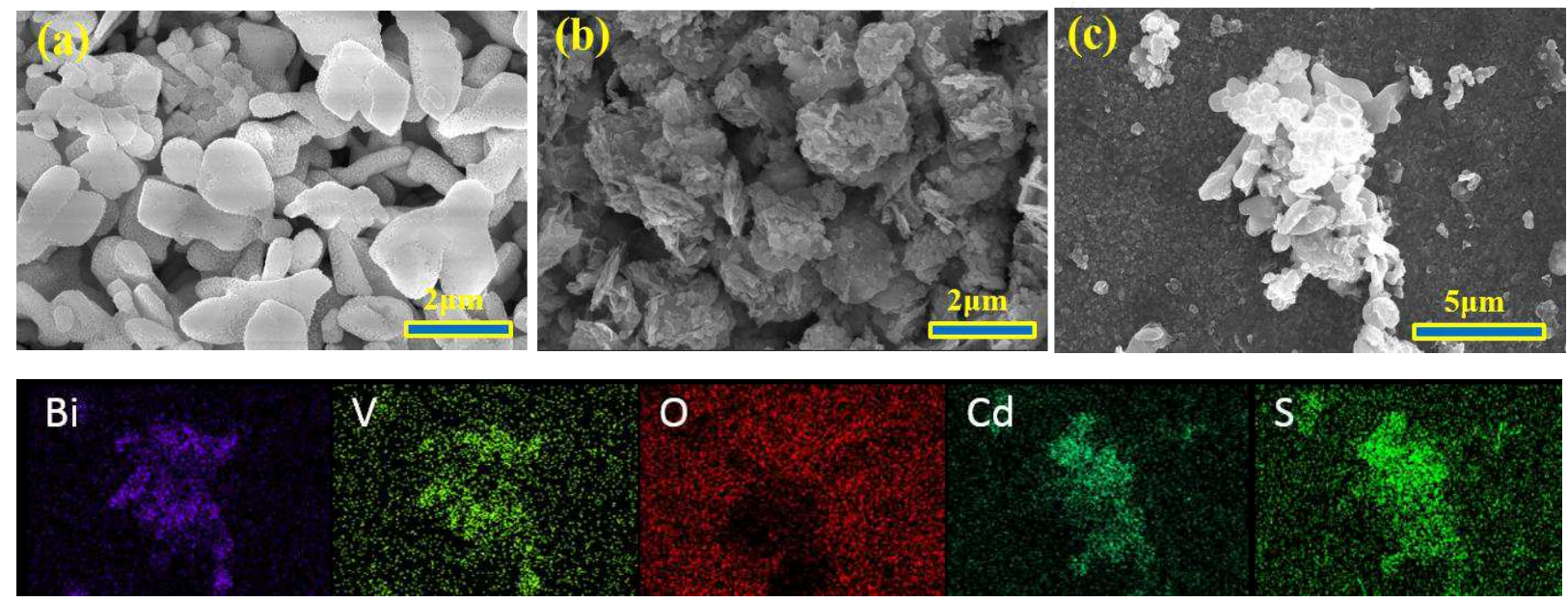

Figure 3. SEM patterns of sample: (a) $\mathrm{BiVO}_{4}$; (b) CdS; (c) CV-3 and the corresponding elements mapping.

In order to establish accurate crystal facets model, detailed information about the crystal facets of $\mathrm{BiVO}_{4}$ and CdS plays a crucial role in heterojunctions. Thus, the synthesized samples $\left(\mathrm{BiVO}_{4}\right.$ and $\left.\mathrm{CdS}\right)$ were characterized by TEM as shown in Figure 4. The nanoparticles of $\mathrm{BiVO}_{4}$ and $\mathrm{CdS}$ presenting agglomerates were observed in Figure $4 \mathrm{a}$ and $4 \mathrm{c}$, respectively. The high-magnification of the TEM images of the localized regions in Figure 4a and $4 \mathrm{c}$ are shown in Figure $4 \mathrm{~b}$ and $4 \mathrm{~d}$, respectively. The clear lattice fringes could be observed, and the lattice distance was measured to be in good agreement with the (010) plane of monoclinic phase $\mathrm{BiVO}_{4}$ and the (100) plane of hexagonal phase CdS.
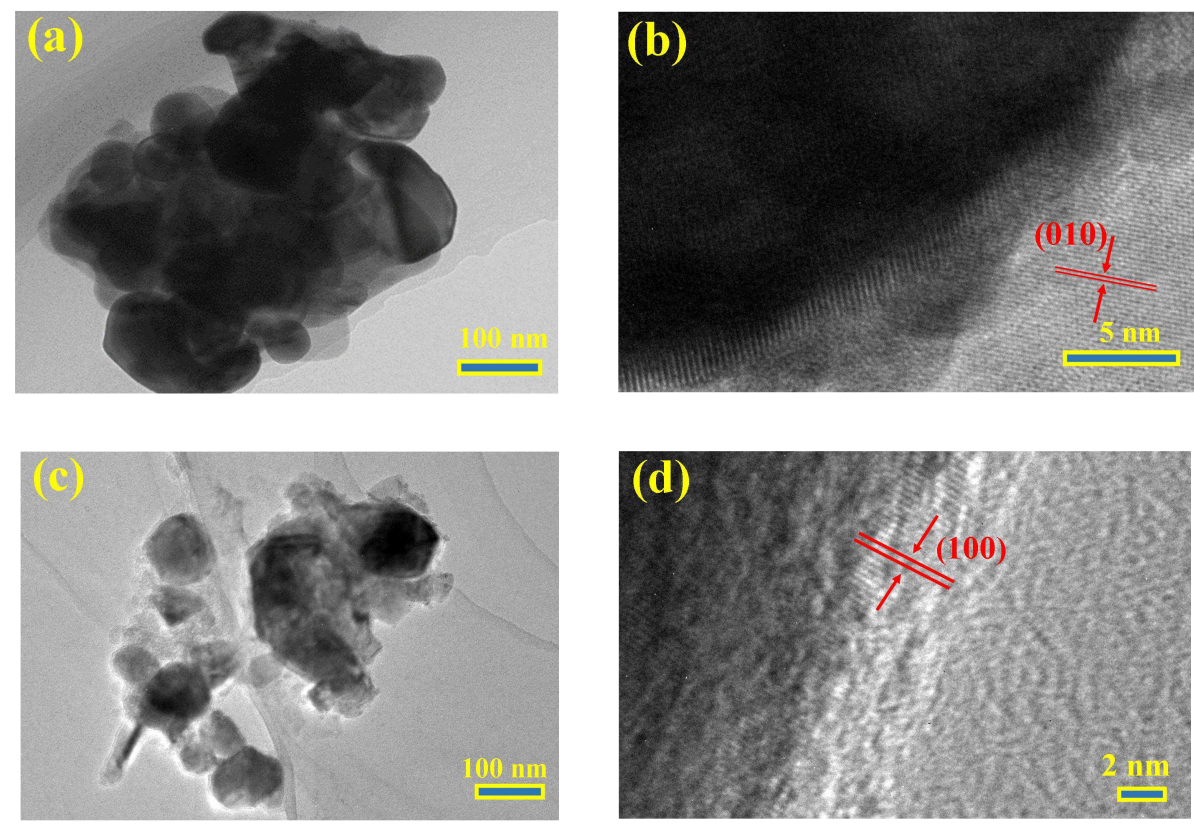

Figure 4. TEM patterns of sample: (a, b) $\mathrm{BiVO}_{4}$; (c, d) CdS. 


\subsection{Photoluminescence spectra}

The photoluminescence (PL) was applied to characterize the recombination probability of photo-generated carriers in the photocatalyst. The PL peaks of $\mathrm{BiVO}_{4}, \mathrm{CdS}$ and $\mathrm{CV}-\mathrm{x}(\mathrm{x}=1 \sim 4)$ were observed in Figure 5. The as-prepared $\mathrm{BiVO}_{4}$ and $\mathrm{CdS}$ exhibited sharp emission peaks at $469 \mathrm{~nm}$ and $494 \mathrm{~nm}$, respectively. Meanwhile, no new emission peaks were observed in $\mathrm{CV}$-x compared to pristine $\mathrm{CdS}$ and $\mathrm{BiVO}_{4}$. The PL intensity of $\mathrm{BiVO}_{4}$ and $\mathrm{CdS}$ is significantly higher than those of $\mathrm{CV}-\mathrm{x}$, which indicates that the photo-generated carriers recombine more rapidly in single phase.

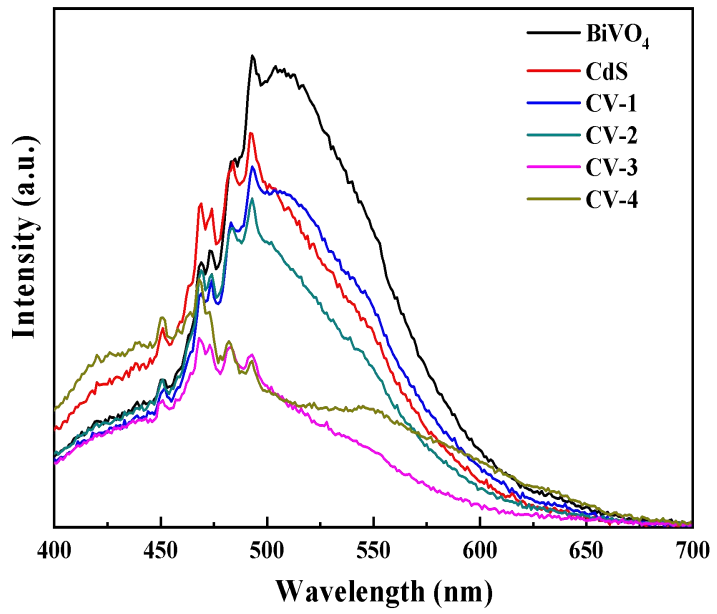

Figure 5. The photoluminescence spectra analysis of $\mathrm{BiVO}_{4}, \mathrm{CdS}$ and $\mathrm{CV}-\mathrm{x}(\mathrm{x}=1 \sim 4)$.

\subsection{Electrochemical performances}

As described in Figure 6a, electrochemical impedance spectroscopy (EIS) was employed to investigate the kinetics of interfacial charge immigration of the pristine $\mathrm{BiVO}_{4}, \mathrm{CV}-\mathrm{x}(\mathrm{x}=1 \sim 4)$ and pristine CdS [42]. The Nyquist curves were measured through a three-electrode system. Generally, the smaller the arc radius, the smaller the interfacial resistance as photo-generated carriers are transferred [40,43]. As the proportion of $\mathrm{BiVO}_{4}$ ascends, the newly formed Z-scheme heterostructures caused the increase of the space separation efficiency of photo-generated carriers and significant diminution of electrochemical resistance in light of the decreasing of the radius of curvature of CV-x $(x=1 \sim 4)$. Nevertheless, when the optimistic ratio was exceeded, the lack of effective interface electric field will lead to the slow transfer of photo-generated carriers on the basis of the increasing the radius of curvature. Consequently, when the ratio is 1:0.75 (CV-3), it is more inclined to accomplish transfer and spatial separation of photo-generated carriers towards the surface reaction sites of the photocatalyst.
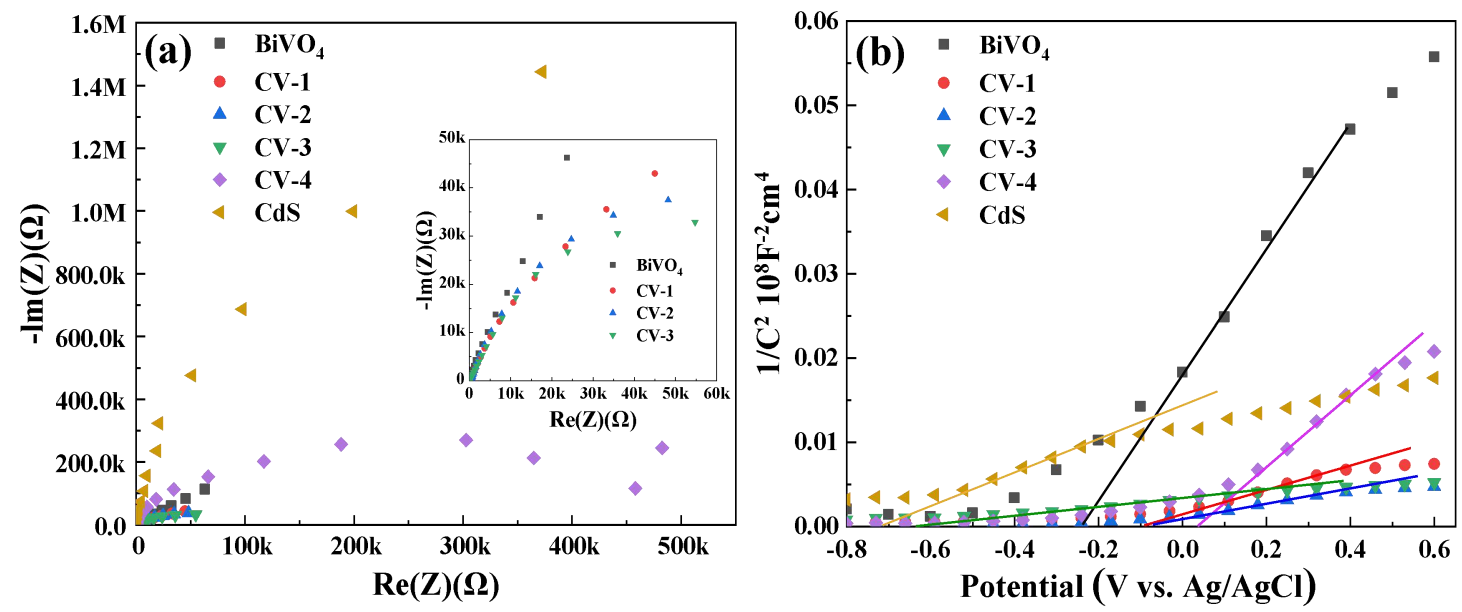

Figure 6. (a) The EIS spectra of samples. (b) The M-S spectra of samples. 
Figure $6 \mathrm{~b}$ displayed the Mott-Schottky spectra of the obtained $\mathrm{BiVO}_{4}, \mathrm{CdS}$ and $\mathrm{CV}-\mathrm{x}(\mathrm{x}=1 \sim 4)$, the measured frequency was $100 \mathrm{~Hz}$. The flat band potential was determined by the tangent of the curve and the intercept of the horizontal axis voltage. Owing to the flat band potential is estimated by $\mathrm{Ag} / \mathrm{AgCl}$ as reference electrode, which is equal to a normal hydrogen electrode (NHE) to be more positive $0.2 \mathrm{~V}$. Consequently, the flat band potential of $\mathrm{BiVO}_{4}, \mathrm{CdS}$ and CV-x is estimated to be $-0.03,0.11,0.08,-0.43,0.22$ and $-0.51 \mathrm{~V}$ (vs NHE), respectively [18]. It was considered that the flat band potential is about $0.1 \mathrm{~V}$ more positive than the conduction band position for most n-type semiconductors, thus the conduction band position can be estimated from the flat band potential. The change in flat band potential is attributed to electron migration caused by alignment of the conduction band and Fermi level as the Z-scheme heterostructure forms. Meanwhile, the flat band potential of $\mathrm{CV}$-x firstly showed a negative shifting and then displayed a positive shifting with the variation of $\mathrm{BiVO}_{4}$ component. Generally, the negative shift could inhibit the recombination of charge carriers by enhancing the band bending at the interface [44]. Therefore, when the composite ratio is 1:0.75 (CV-3), the separation of space charge can be better promoted. In addition, the carrier concentration of the semiconductor photocatalyst can be estimated by the slope of the curve. The carrier concentration can be determined by the formula:

$$
N_{d}=\left(2 / e_{0} \varepsilon_{0} \varepsilon\right)\left[d\left(1 / C^{2}\right) / d V\right]^{-1}
$$

Among them, $N_{d}$ and $\mathrm{C}$ are the carrier density and interface capacitance, $\mathrm{e}_{0}$ is the amount of charge carried by an electron, $\varepsilon$ is the dielectric constant, $\varepsilon_{0}$ is vacuum permittivity and, $V$ is the applied voltage [45]. According to calculations, the carrier densities of $\mathrm{BiVO}_{4}, \mathrm{CV}-\mathrm{x}(\mathrm{x}=1 \sim 4)$ and $\mathrm{CdS}$ are $2.92 \times 10^{23}, 7.08 \times 10^{24}, 9.64 \times 10^{24}, 1.55 \times 10^{25}$ and $9.46 \times 10^{23}$ and $6.04 \times 10^{24} \mathrm{~cm}^{-3}$, respectively. The results indicate that the formation of the Z-scheme heterostructure can effectively increase the carrier density.

\subsection{Photocatalytic performance}

As shown in Figure 7a, the photocatalytic properties of the obtained $\mathrm{CdS}, \mathrm{BiVO}_{4}$ and $\mathrm{CV}-\mathrm{x}(\mathrm{x}=1 \sim 4)$ were monitored by photodegradation of $\mathrm{MO}$ at $65{ }^{\circ} \mathrm{C}$ under visible light irradiation. The darkness status was maintained for $30 \mathrm{~min}$ to eliminate the disturbing of physical adsorption, and then the photodegradation experiment was carried out after the balance of adsorption and desorption was reached. After visible light irradiation for 150 min, the photocatalytic degradation efficiency of $\mathrm{BiVO}_{4}, \mathrm{CdS}$ and $\mathrm{CV}-\mathrm{x}(\mathrm{x}=1 \sim 4)$ were $67.9 \%, 55.8 \%, 71.4 \%, 72.2 \%$, $90.6 \%$ and $78.6 \%$, respectively. Compared to $\mathrm{BiVO}_{4}$ and $\mathrm{CdS}$, the photocatalytic degradation efficiency of $\mathrm{CV}-\mathrm{x}$ was significantly improved and the degradation efficiency of CV-3 reached $90.6 \%$. According to the Langmuir-Hinshelwood (L-H) kinetic model: $\ln \left(C_{0} / C_{t}\right)=k t$, where $C_{0}$ and $C_{t}$ are MO concentration $\left(\mathrm{mg} \mathrm{L}^{-1}\right)$ before and after irradiation, $t$ is time $(\mathrm{min}), k$ is apparent reaction rate constant $\left(\mathrm{min}^{-1}\right)$. Photocatalytic kinetics can be represented by a pseudo-first-order kinetic model to eliminate the effect of adsorption on MO decolorization. The fitting results are shown in Figure 7b. It shows that the $k$ value of CV-3 $\left(k=9.78 \times 10^{-3} \mathrm{~min}^{-1}\right)$ is 1.82 and 1.39 times than those of individual $\mathrm{BiVO}_{4}\left(k=5.36 \times 10^{-3} \mathrm{~min}^{-1}\right)$ and $\mathrm{CdS}\left(k=7.00 \times 10^{-3} \mathrm{~min}^{-1}\right)$ under the same condition, respectively.

The photocatalytic performances of the prepared $\mathrm{CdS}, \mathrm{BiVO}_{4}$ and $\mathrm{CV}-\mathrm{x}(\mathrm{x}=1 \sim 4)$ were also evaluated by photodegradation of $\mathrm{RhB}$ at $65{ }^{\circ} \mathrm{C}$ under visible light irradiation as shown in Figure $7 \mathrm{c}$. After visible light irradiation for $75 \mathrm{~min}$, the degradation rates of $\mathrm{BiVO}_{4}, \mathrm{CdS}$ and $\mathrm{CV}-\mathrm{x}$ to $\mathrm{RhB}$ were $44.7 \%, 34.2 \%, 89.1 \%, 95.9 \%$, $97.9 \%$ and $80.1 \%$ respectively and the degradation rate of CV-3 was still highest among all samples. According to the pseudo-first-order kinetic mode (Figure 7d), it can be seen that the reaction rate constant of CV-3 $(k=4.39 \times$ $\left.10^{-2} \mathrm{~min}^{-1}\right)$ is 6.2 and 9.4 times than those of $\mathrm{BiVO}_{4}\left(k=7.09 \times 10^{-3} \mathrm{~min}^{-1}\right)$ and $\mathrm{CdS}\left(k=4.68 \times 10^{-3} \mathrm{~min}^{-1}\right)$, respectively. Because CV-x $(x=1 \sim 4)$ formed direct $Z$-scheme heterostructure inhibiting the recombination of photo-generated carriers and providing more reaction sites, the photocatalytic activities were effectively improved. Among them, CV-3 exhibited the most superior photocatalytic activity. However, when the $\mathrm{BiVO}_{4}$ content was further increased, the photocatalytic activity decreased. However, the photocatalytic activity decreases when the 
$\mathrm{BiVO}_{4}$ content is further increased, which may be caused by the insufficient composition of $\mathrm{BiVO}_{4}$ and $\mathrm{CdS}$ and the lower conduction band of $\mathrm{BiVO}_{4}$ [40]. These cycling experiments of $\mathrm{RhB}$ degradation were applied to examine their interaction force and possible the photo-corrosion phenomenon of sulfide and in the CV-3 as shown in Figure 7e. After three cycles of experiments, the photocatalytic degradation rate of CV-3 slightly reduced from $90.6 \%$ to $81.1 \%$ [46]. Therefore, the strong electrostatic attraction at the interface prevents the separation and shedding of $\mathrm{CdS}$ and $\mathrm{BiVO}_{4}$, at the same time the $\mathrm{Z}$-scheme heterostructure increase the stability of sulfide [47].
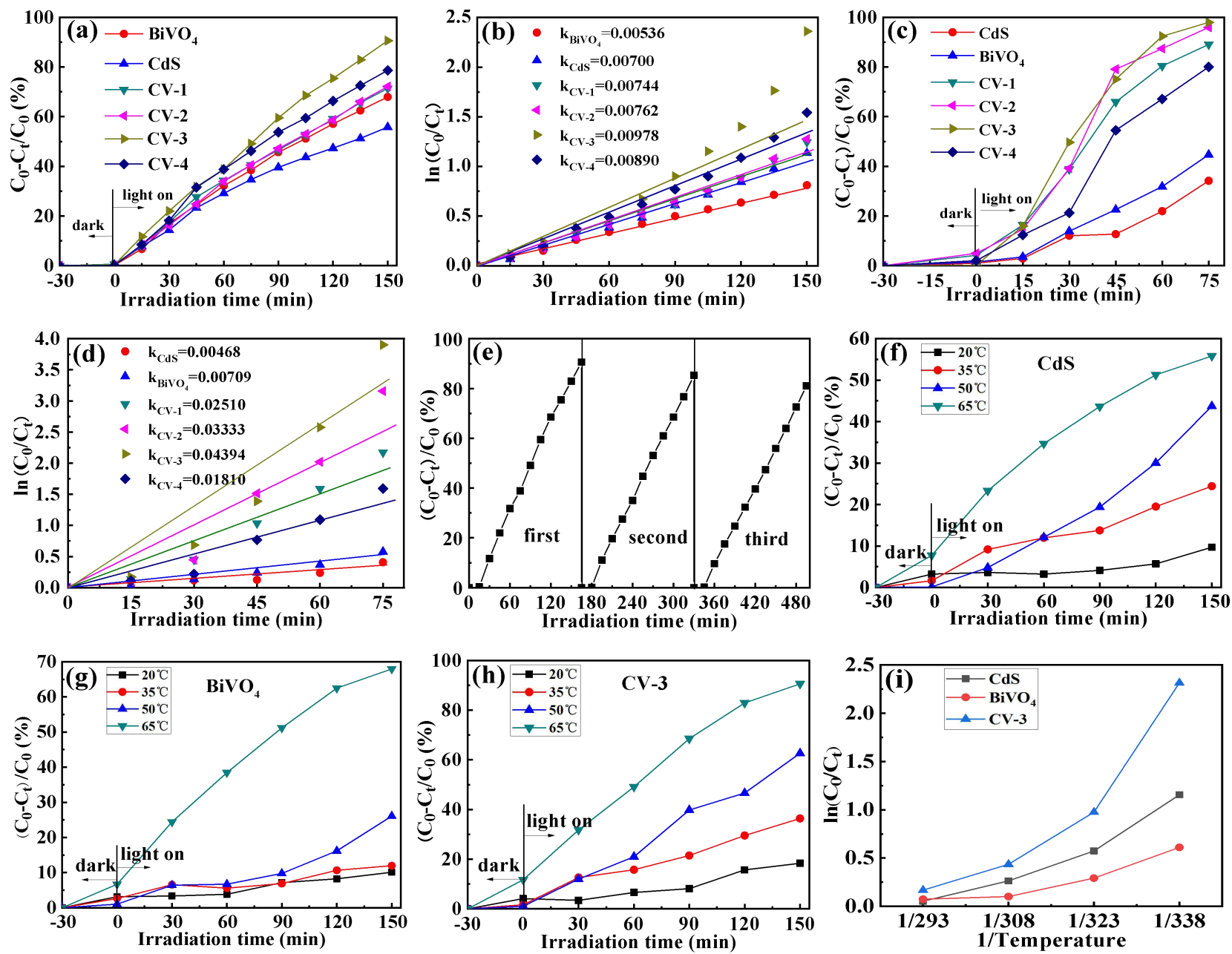

Figure 7. (a) Photocatalytic degradation of MO with the prepared samples under visible light irradiation. (b) Photocatalytic kinetic rates of MO with the prepared samples. (c) Photocatalytic degradation of RhB with the prepared samples under visible light irradiation. (d) Photocatalytic kinetic rates of RhB with the prepared samples. (e) Cycling experiments of CV-3 composite for the degradation of MO under visible light irradiation. (f-h) Photocatalytic experiment of CdS, $\mathrm{BiVO}_{4}$ and CV-3 degradation of MO at different temperatures. (i) Kinetics of degradation rate of $\mathrm{CdS}, \mathrm{BiVO}_{4}$ and $\mathrm{CV}-3$ with temperature. $\mathrm{RhB}$ and $\mathrm{MO}$ dye concentration: $10 \mathrm{mg} \mathrm{L}^{-1}$, $\mathrm{pH}=7$.

Figures 7 (f-h) show the photocatalytic degradation of $\mathrm{MO}$ at $20^{\circ} \mathrm{C}, 35^{\circ} \mathrm{C}, 50{ }^{\circ} \mathrm{C}$, and $65{ }^{\circ} \mathrm{C}$ of $\mathrm{CdS}, \mathrm{BiVO}_{4}$, and CV-3 under visible light irradiation. After $30 \mathrm{~min}$ of dark treatment, there was no particular difference in the adsorption effect of the same sample at different temperatures. After starting the irradiation, the degradation rate enhanced significantly with increasing temperature. At $65^{\circ} \mathrm{C}$, the degradation efficiency of pure $\mathrm{BiVO}_{4}$ and $\mathrm{CdS}$ is only $67.9 \%$ and $55.8 \%$, respectively, while the degradation efficiency of CV-3 has reached about $90.8 \%$. The degradation efficiency of CV-3 remained superior to those of $\mathrm{BiVO}_{4}$ and $\mathrm{CdS}$ in the remaining three temperatures, except at $65^{\circ} \mathrm{C}$. It can be inferred that the rise in temperature provides sufficient activation energy to the reaction 
system and increases the content of activating molecules, which is conducive to enhancing the photocatalytic degradation efficiency. Figure $7 \mathrm{i}$ displays the relationship between the degradation rate kinetics of $\mathrm{CdS}_{\mathrm{S}} \mathrm{BiVO}_{4}$, CV-3 and temperature. It can be clearly seen that the degradation rate kinetics is inversely proportional to the reciprocal of temperature. We know that, activation energy can be calculated by Arrhenius formula $(\ln k=\ln Z-$ $\left.E_{a} / R T\right)$, where the $k$ represents the degradation reaction rate, $\operatorname{lnZ}$ refers to the pre-factor or frequency factor, $E_{a}$ is the activation energy of the reaction. According to the Arrhenius formula, the $E_{a}$ values of CdS, $\mathrm{BiVO}_{4}$ and CV-3 are $55.4 \mathrm{~kJ} / \mathrm{mol}, 40.3 \mathrm{~kJ} / \mathrm{mol}$ and $47.7 \mathrm{~kJ} / \mathrm{mol}$ by linear fitting of lnk $1 / \mathrm{T}$. Their activation energies are one order of magnitude. Table 1 shows the comparison of the degradation rates of CV-3 with previously reported CdS-based or $\mathrm{BiVO}_{4}$-based photocatalysts. Obviously, this CV-3 exhibited superior degradation rates under weaker irradiation intensities and less photocatalyst content. This enhancement may be attributed to the presence of electrostatic gravity at the heterojunction of CV-3 due to promoting the transfer and separation of photo-generated carriers.

Table 1. Comparison results of degradation rate with typical photocatalysts in photodegrading MO and RhB.

\begin{tabular}{|c|c|c|c|c|c|c|c|}
\hline Photocatalyst & $\begin{array}{c}\text { Degradation } \\
\text { efficiency } \\
\left(\mathrm{C} / \mathrm{C}_{0}\right)\end{array}$ & $\begin{array}{c}\text { Photocatalyst } \\
\text { content (g) }\end{array}$ & $\begin{array}{l}\text { Organic } \\
\text { pollutant }\end{array}$ & $\begin{array}{c}\text { Pollutant } \\
\text { concentration } \\
(\mathrm{g} / \mathrm{L})\end{array}$ & $\begin{array}{c}\text { Degradation } \\
\text { rate }\left(\min ^{-1} \cdot \mathrm{g}^{-1}\right)\end{array}$ & Illuminant & Ref. \\
\hline \multirow[t]{2}{*}{$\mathrm{CdS} / \mathrm{BiVO}_{4}$} & 90.6 & 0.009 & $\mathrm{MO}$ & $1.0 \times 10^{-2}$ & 1.09 & $300 \mathrm{~W}$ Xe lamp & This work \\
\hline & 97.9 & 0.009 & RhB & $1.0 \times 10^{-2}$ & 4.88 & $300 \mathrm{~W}$ Xe lamp & This work \\
\hline $\mathrm{BiVO}_{4} / \mathrm{Ag} / \mathrm{CdS}$ & 90.0 & 0.02 & RhB & $5.0 \times 10^{-3}$ & 0.73 & $500 \mathrm{~W}$ Xe lamp & {$[48]$} \\
\hline $\mathrm{BiVO}_{4} / \mathrm{g}-\mathrm{C}_{3} \mathrm{~N}_{4}$ & 100.0 & 0.10 & RhB & $2.0 \times 10^{-2}$ & 0.28 & $500 \mathrm{~W}$ halogen lamp & [49] \\
\hline $\mathrm{CdS} / \mathrm{TiO}_{2}$ & 98.9 & 0.30 & RhB & $5.0 \times 10^{-3}$ & 0.04 & $500 \mathrm{~W}$ Xe lamp & {$[50]$} \\
\hline $\mathrm{BiVO}_{4} / \mathrm{BiOI}$ & 97.0 & 0.03 & $\mathrm{RhB}$ & $1.0 \times 10^{-2}$ & 0.61 & $500 \mathrm{~W}$ Xe lamp & [43] \\
\hline $\mathrm{CdS} / \mathrm{ZnO}$ & 94.6 & 0.10 & MO & $5.0 \times 10^{-3}$ & 0.14 & $500 \mathrm{~W}$ halogen lamp & [51] \\
\hline
\end{tabular}

\subsection{Photocatalytic mechanism of $\mathrm{CdS} / \mathrm{BiVO}_{4}$}

The typical crystal facet features of $\mathrm{BiVO}_{4}$ and $\mathrm{CdS}$ could be obtained by TEM. And the electron-hole transfer path was probed by the calculation of the electrostatic potential. Then, the surfaces of (010) and (100) were cleaved from $\mathrm{BiVO}_{4}$ cell and $\mathrm{CdS}$ cell (Figure 8 and 9). Here a vacuum distance of $15 \AA$ in model with periodicity. The electrostatic potential is calculated by the formula, $\Phi=E_{\text {Vacuum }}-E_{f}$, where the $\Phi$ is the work function, $E_{\text {Vacum }}$ is the vacuum energy level, and $E_{f}$ is the Fermi energy level. The results are as follows, $\Phi_{\mathrm{BiVO}}=6.52 \mathrm{eV}$ and $\Phi_{\mathrm{CdS}}=$ $4.81 \mathrm{eV}$, respectively. The difference in the electrostatic potential between $\mathrm{BiVO}_{4}$ surface and the (100) CdS surface is $\Delta \Phi=1.71 \mathrm{eV}$.
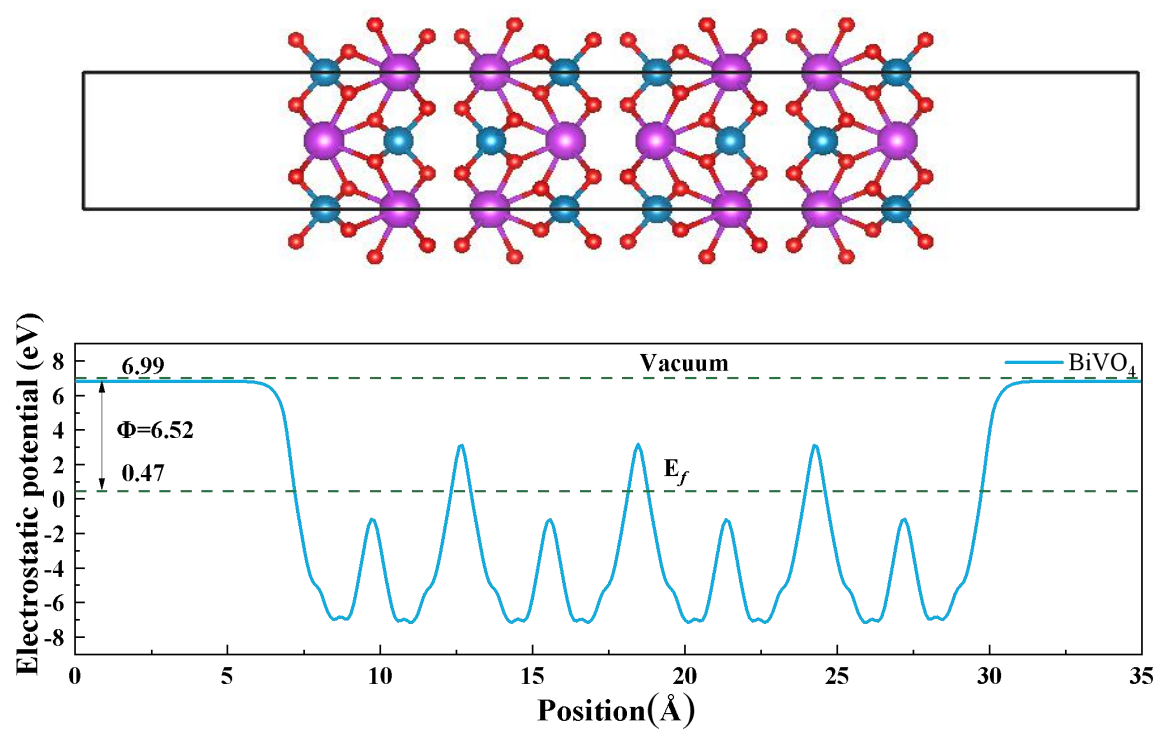

Figure 8. Electrostatic potential of $\mathrm{BiVO}_{4}$ slab structure (blue, red and purple atoms are $\mathrm{V}, \mathrm{O}$ and $\mathrm{Bi}$ ). 

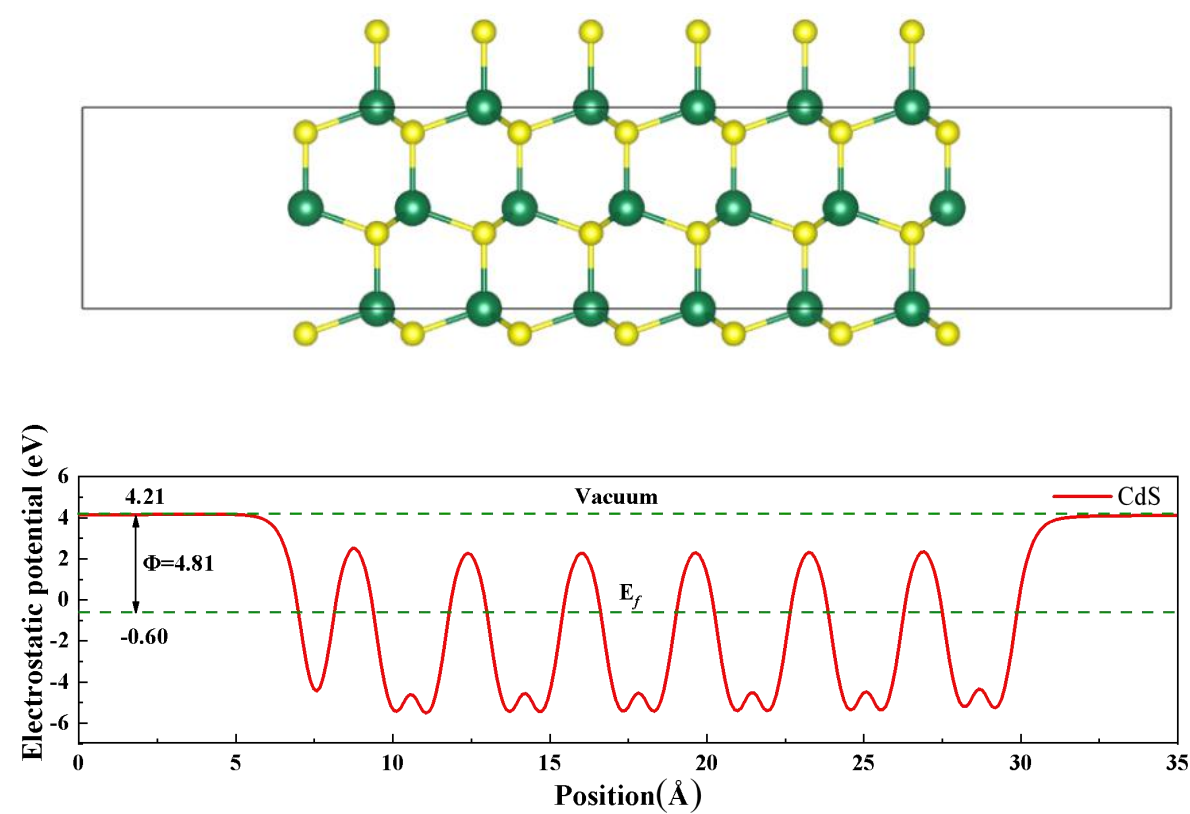

Figure 9. Electrostatic potential of CdS slab structure (green and yellow atoms are Cd and S).

According to previous report, the difference in the electrostatic potential can be used to judge the migrating of photo-generated electrons [37]. As a result, the photo-generated electrons on the CdS can be more easily transferred to the $\mathrm{BiVO}_{4}$ at the $\mathrm{CV}-\mathrm{x}(\mathrm{x}=1 \sim 4)$ heterojunction. Photo-generated electrons are initially migrated until the Fermi energy levels are aligned. Consequently, the upward bending of the valence band of $\mathrm{CdS}$ and the downward bending of the conduction band of $\mathrm{BiVO}_{4}$ are caused by the transfer of photo-generated electrons. As mentioned above, the conduction band positions of CdS, $\mathrm{BiVO}_{4}$ and $\mathrm{CV}-3$ can be estimated to be $-0.61 \mathrm{eV},-0.13 \mathrm{eV}$ and -0.53 $\mathrm{eV}$, respectively. Simultaneously, through the previously reported works by our group and other group, it can be determined that the band gaps of $\mathrm{BiVO}_{4}$ and $\mathrm{CdS}$ are 2.43 and $2.40 \mathrm{eV}$, respectively [40,52]. Meanwhile, the valence band position can be calculated to be $2.30 \mathrm{eV}$ and $1.79 \mathrm{eV}$ respectively by $E_{V B}=E_{C B}+E_{g}$. We can reasonably infer that the $\mathrm{VB}$ of $\mathrm{CdS}$ and the $\mathrm{CB}$ of $\mathrm{BiVO}_{4}$ lead to the recombination of photo-generated carriers through the path of the Z-scheme heterojunction [46,53,54]. Thus, a direct Z-scheme heterostructure was constructed by electrostatic attraction at the interface (Figure 10).

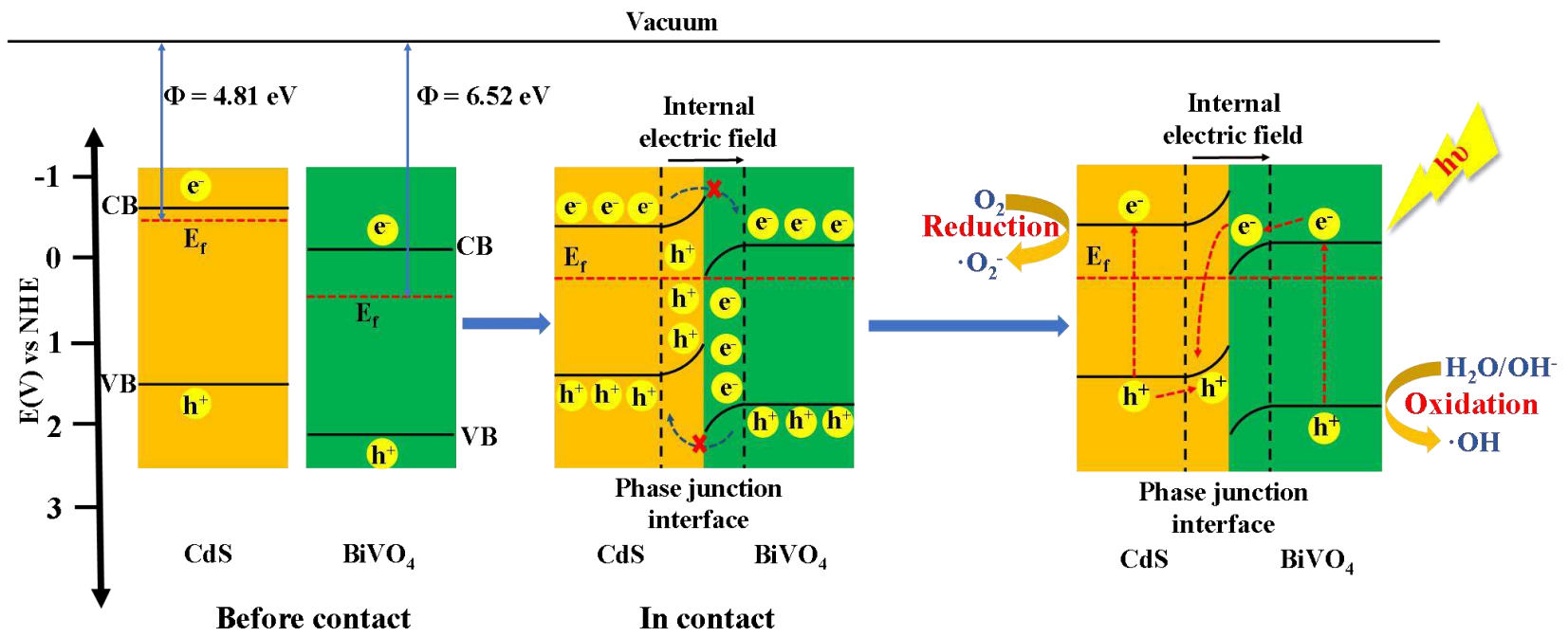

Figure 10. Schematic diagram of Z-scheme heterojunction formation mechanism of CV-3. 
Under the irradiation of incident light, the photo-generated electrons in $\mathrm{CB}$ of $\mathrm{BiVO}_{4}$ and holes in $\mathrm{VB}$ of $\mathrm{CdS}$ would migrate and recombine in the interface between $\mathrm{BiVO}_{4}$ and $\mathrm{CdS}$ under the action of the built-in electric field, resulting in continuous accumulation of electrons and holes in $\mathrm{CB}$ of $\mathrm{CdS}$ and $\mathrm{VB}$ of $\mathrm{BiVO}_{4}$, thus achieving the enhanced photocatalytic activity $[19,40]$. Meanwhile, the continuous depletion of holes in VB of CdS retards the oxidation of $\mathrm{S}^{2-}$, which could restrain the photo-corrosion of the CdS component. Eventually, the photo-generated electrons in $\mathrm{CB}$ of $\mathrm{CdS}$ will generate $\cdot \mathrm{O}_{2}{ }^{-}$with adsorbed $\mathrm{O}_{2}$ at the surface, and photo-generated holes in $\mathrm{VB}$ of $\mathrm{BiVO}_{4}$ will react with water to form $\cdot \mathrm{OH}$. In the photocatalytic process, these active groups could promote the whole photodegradation process.

\section{Conclusion}

In summary, our study showed that this convenient and effective approach of electrophoretic deposition can form a direct Z-scheme heterostructure between $\mathrm{CdS}$ and $\mathrm{BiVO}_{4}$, which exhibited excellent photocatalytic activities under visible light irradiation. The results of EIS and PL revealed that the CV-x system could enhance the separation and transfer of the photo-generated carriers. In the photocatalytic experiments with controlled temperature, the activation energy of CV-3 showed slight difference compared with $\mathrm{CdS}$ and $\mathrm{BiVO}_{4}$. It demonstrates that the superior photocatalytic activities of CV-3 originate from well separation and transfer of photo-generated carriers. Besides, the cycling experiments demonstrate that the stability of CV-x can be well maintained by electrostatic attraction at the interface between $\mathrm{BiVO}_{4}$ and $\mathrm{CdS}$.

\section{Acknowledgment}

The authors gratefully acknowledge financial supports from the Education Department Program of Heilongjiang Province (12541111) and Postdoctoral Scientific Developmental Fund of Heilongjiang Province (LBH-Q16122).

\section{REFERENCES}

1. S. Ni, T. Zhou, H. Zhang, Y. Cao, P. Yang, ACS Appl. Nano Mater. 1, 5128-5141 (2018)

2. F. Chen, Q. Yang, J. Sun, F. Yao, S. Wang, Y. Wang, X. Wang, X. Li, C. Niu, D. Wang, G. Zeng, ACS Appl. Mater. Interfaces 8, 32887-32900 (2016)

3. G. Wang, F. Zhou, B. Yuan, S. Xiao, A. Kuang, M. Zhong, S. Dang, X. Long, W. Zhang, Nanomaterials-basel 9, 244-253 (2019)

4. L. Shan, Y. Liu, J. Mol. Catal. A: Chem. 416, 1-9 (2016)

5. J. Li, L. Cai, J. Shang, Y. Yu, L. Zhang, Adv. Mater. Processes 28, 4059-4064 (2016)

6. C. Li, P. Zhang, R. Lv, J. Lu, T. Wang, S. Wang, H. Wang, J. Gong, Small 9, 3950-3956 (2013)

7. L. Shan, G. Wang, D. Li, X. San, L. Liu, L. Dong, Z. Wu, Dalton Trans. 44, 7835-7843 (2015)

8. L. Dong, D. Liu, H. Fu, X. Li, L. Shan, J. Inorg. Organomet. Polym. Mater. 29, 1297-1304 (2019)

9. J. Li, K. Zhao, Y. Yu, L. Zhang, Adv. Funct. Mater. 25, 2189-2201 (2015)

10. S. K. Cho, H. S. Park, H. C. Lee, K. M. Nam, A. J. Bard, J. Phys. Chem. C 117, 23048-23056 (2013)

11. J. Di, J. X. Xia, M. X. Ji, B. Wang, X. W. Li, Q. Zhang, Z. G. Chen, H. M. Li, ACS Sustain. Chem. Eng. 4, 136-146 (2015)

12. A. Y. Booshehri, S. Chun-Kiat Goh, J. Hong, R. Jiang, R. Xu, J. Mater. Chem. A 2, 6209-6217 (2014)

13. M. Xing, B. Qiu, M. Du, Q. Zhu, L. Wang, J. Zhang, Adv. Funct. Mater. 27, 1702624-1702633 (2017)

14. J. Jiang, X. Zhang, P. Sun, L. Zhang, J. Phys. chem. C 115, 20555-20564 (2011)

15. J. Cao, B. Y. Xu, H. L. Lin, B. D. Luo, S. F. Chen, Chem. Eng. J. 185-186, 91-99 (2012)

16. J. Hu, X. Li, X. Wang, Q. Li, F. Wang, Dalton Trans. 48, 8937-8947 (2019)

17. H. Huang, K. Xiao, X. Du, Y. Zhang, ACS Sustainable Chem. Eng. 5, 5253-5264 (2017) 
18. C. Zeng, Y. Hu, T. Zhang, F. Dong, Y. Zhang, H. Huang, J. Mater. Chem. A 6, 16932-16942 (2018)

19. J. Low, J. Yu, M. Jaroniec, S. Wageh, A. A. Al-Ghamdi, Adv. Mater. 29, 1601694-1601713 (2017)

20. P. J. Sophia, D. Balaji, T. James Caleb Peters, D. S. Chander, S. Vishwath Rishaban, P. Vijaya Shanthi, K. R. Nagavenkatesh, M. R. Kumar, ChemistrySelect 5, 4125-4135 (2020)

21. Z. He, Y. Shi, C. Gao, L. Wen, J. Chen, S. Song, J. Phys. chem. C 118, 389-398 (2013)

22. N. C. Castillo, A. Heel, T. Graule, C. Pulgarin, Appl. Catal. B: Environ. 95, 335-347 (2010)

23. T. Ahmed, H. L. Zhang, Y. Y. Gao, H. B. Xu, Y. Zhang, Mater. Res. Bull. 99, 298-305 (2018)

24. J. Liu, J. Phys. chem. C 119, 28417-28423 (2015)

25. S. R. Kadam, S. W. Gosavi, B. B. Kale, N. Suzuki, C. Terashima, A. Fujishima, Sci. Rep. 9, 12036-12045 (2019)

26. B. Li, Y. Wang, J. Phys. Chem. Solids 72, 1165-1169 (2011)

27. S. Kumar, S. Khanchandani, M. Thirumal, A. K. Ganguli, ACS Appl. Mater. Interfaces 6, 13221-13233 (2014)

28. X. Yang, Z. Yan, L. Jiang, X. Wang, K. Zheng, Y. Wang, Q. Li, J. Wang, Procedia Environ. Sci. 18, $572-578$ (2013)

29. S. S. Srinivasan, J. Wade, E. K. Stefanakos, J. Nanomater. 2006, 1-7 (2006)

30. D. Ke, T. Peng, L. Ma, P. Cai, P. Jiang, Appl. Catal., A 350, 111-117 (2008)

31. Y. F. Ma, H. Q. Jiang, X. C. Zhang, J. B. Xing, Y. S. Guan, Ceram. Int. 40, 16485-16493 (2014)

32. Z. F. Huang, L. Pan, J. J. Zou, X. Zhang, L. Wang, Nanoscale 6, 14044-14063 (2014)

33. D. S. R. Josephine, B. Sakthivel, K. Sethuraman, A. Dhakshinamoorthy, ChemistrySelect 1, 2332-2340 (2016)

34. R. Shi, H.-F. Ye, F. Liang, Z. Wang, K. Li, Y. Weng, Z. Lin, W.-F. Fu, C.-M. Che, Y. Chen, Adv. Mater. 30, 1705941-1705946 (2018)

35. B. O. Orimolade, O. A. Arotiba, Sci. Rep. 10, 5348-5360 (2020)

36. T. Liu, R. Liu, Q. Li, J. Yang, ACS Sustainable Chem. Eng. 8, 1980-1988 (2020)

37. T. Liu, Q. Zhao, C. Li, Y. Lyu, M. Dupuis, J. Phys. chem. C 123, 20142-20151 (2019)

38. J. Zhang, F. Ren, M. Deng, Y. Wang, PCCP 17, 10218-10226 (2015)

39. W. Wang, P. J. Strohbeen, D. Lee, C. Zhou, J. K. Kawasaki, K.-S. Choi, M. Liu, G. Galli, Chem. Mater. 32, 2899-2909 (2020)

40. L. Zou, H. Wang, X. Wang, ACS Sustainable Chem. Eng. 5, 303-309 (2016)

41. M. Yan, Y. Wu, Y. Yan, X. Yan, F. Zhu, Y. Hua, W. Shi, ACS Sustainable Chem. Eng. 4, 757-766 (2015)

42. L. Shan, Y. Liu, J. Bi, J. Suriyaprakash, Z. Han, J. Alloys Compd. 721, 784-794 (2017)

43. H. Huang, Y. He, X. Du, P. K. Chu, Y. Zhang, ACS Sustainable Chem. Eng. 3, 3262-3273 (2015)

44. L. Shan, C. Lu, L. Dong, J. Suriyaprakash, J. Alloys Compd. 804, 385-391 (2019)

45. G. Zhang, L. Zhang, Y. Liu, L. M. Liu, C. P. Huang, H. J. Liu, J. H. Li, ACS Appl. Mater. Interfaces 8, 26783-26793 (2016)

46. F. Q. Zhou, J. C. Fan, Q. J. Xu, Y. L. Min, Appl. Catal., B 201, 77-83 (2017)

47. T. Su, Q. Shao, Z. Qin, Z. Guo, Z. Wu, ACS Catal. 8, 2253-2276 (2018)

48. L. Zou, H. Wang, C. Wu, L. Li, G. Yuan, X. Wang, Appl. Surf. Sci. 498, 143900-143928 (2019)

49. P. Cui, Y. Hu, M. Zheng, C. Wei, Environ. Sci. Pollut. Res. 25, 32466-32477 (2018)

50. H. Wang, J. Li, H. Zhou, S. Yao, W. Zhang, J. Mater. Sci.: Mater. Electron. 30, 10754-10764 (2019)

51. L. An, G. Wang, Y. Cheng, L. Zhao, F. Gao, Y. Cheng, Russ. J. Phys. Chem. A 89, 1878-1883 (2015)

52. L. Shan, J. Bi, C. Lu, Y. Xiao, J. Inorg. Organomet. Polym. Mater. 29, 1000-1009 (2018)

53. F. Liu, R. Shi, Z. Wang, Y. Weng, C. M. Che, Y. Chen, Angew. Chem., Int. Ed. Engl. 58, 11791-11795 (2019)

54. Y. Cheng, X. Kong, Y. Chang, Y. Feng, R. Zheng, X. Wu, K. Xu, X. Gao, H. Zhang, Adv. Mater. 32, 1908109-1908117 (2020) 


\section{Graphic abstract}

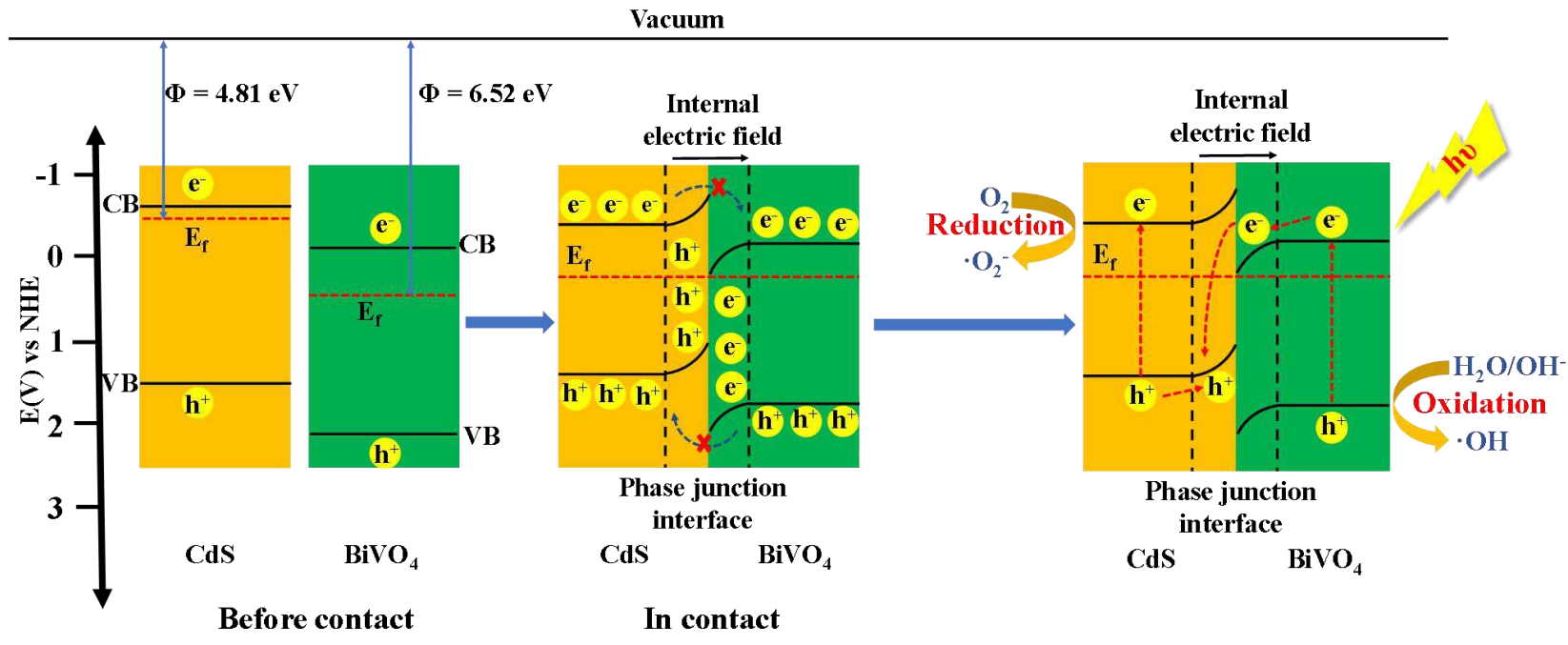


Figures

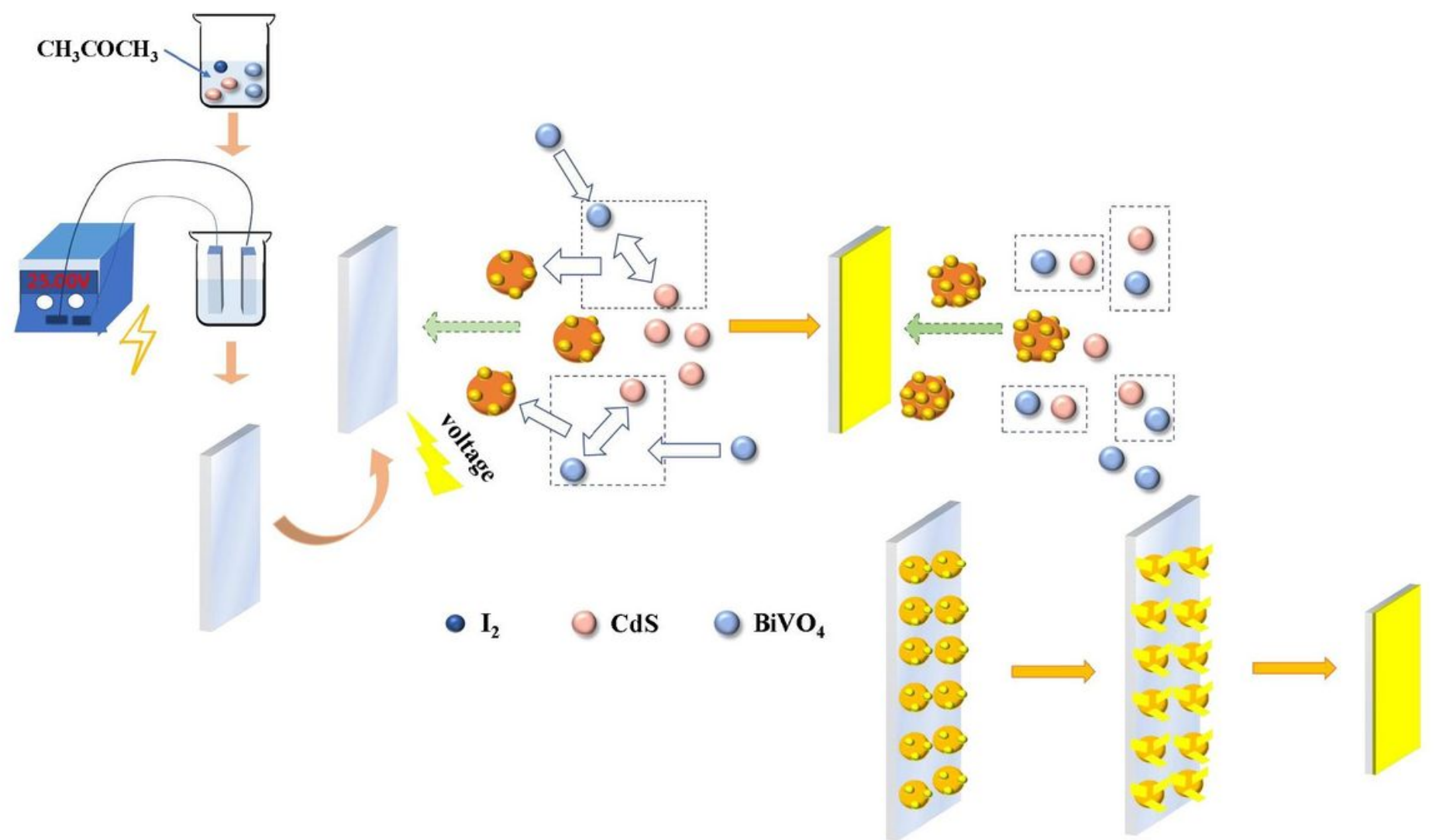

Figure 1

Formation mechanism of electrophoretic deposition of CdS/BiVO4 

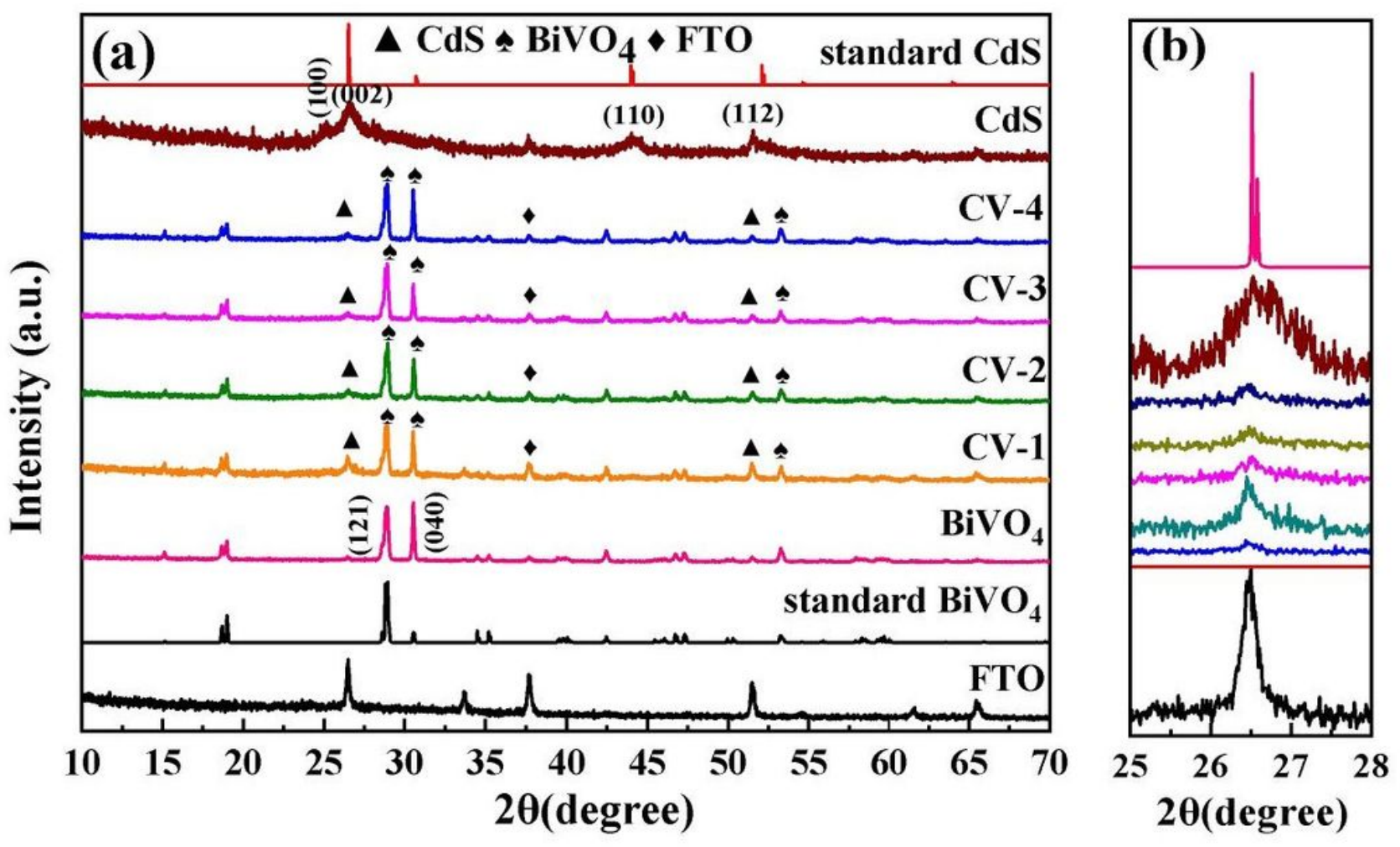

Figure 2

Please see the Manuscript PDF file for the complete figure caption
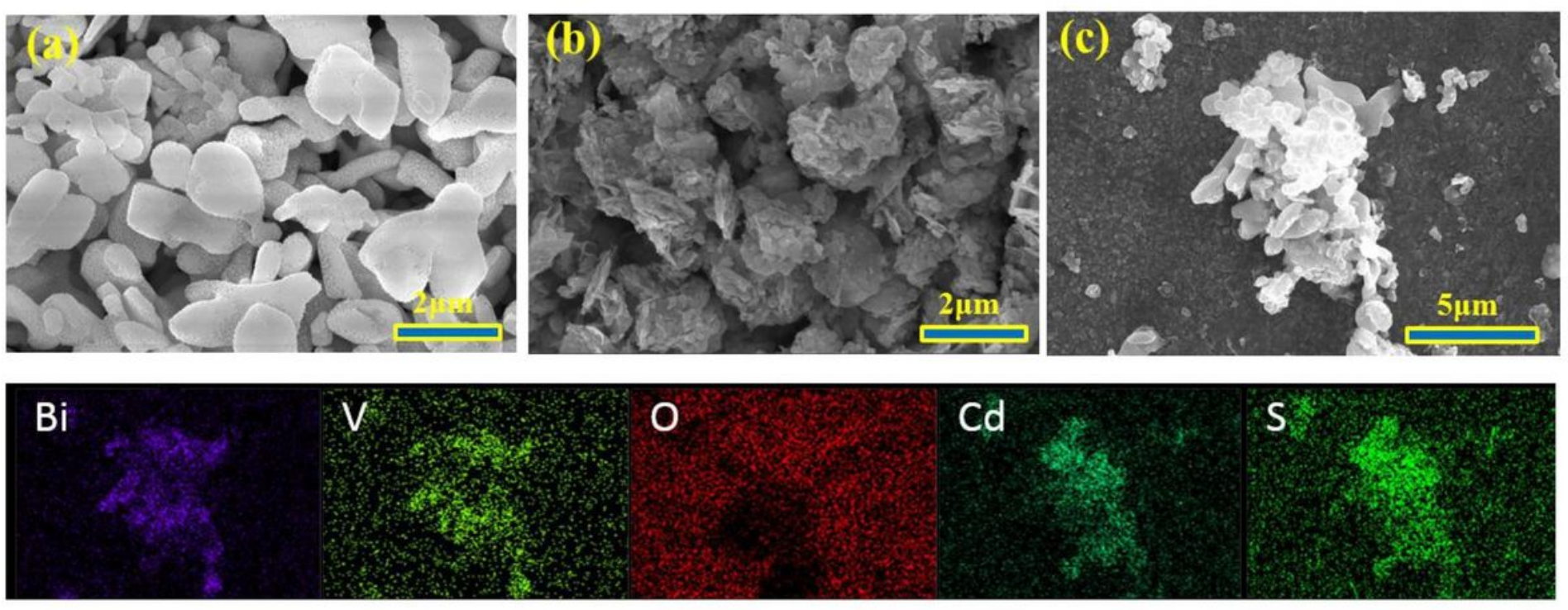

Figure 3

SEM patterns of sample: (a) BiVO4; (b) CdS; (c) CV-3 and the corresponding elements mapping 

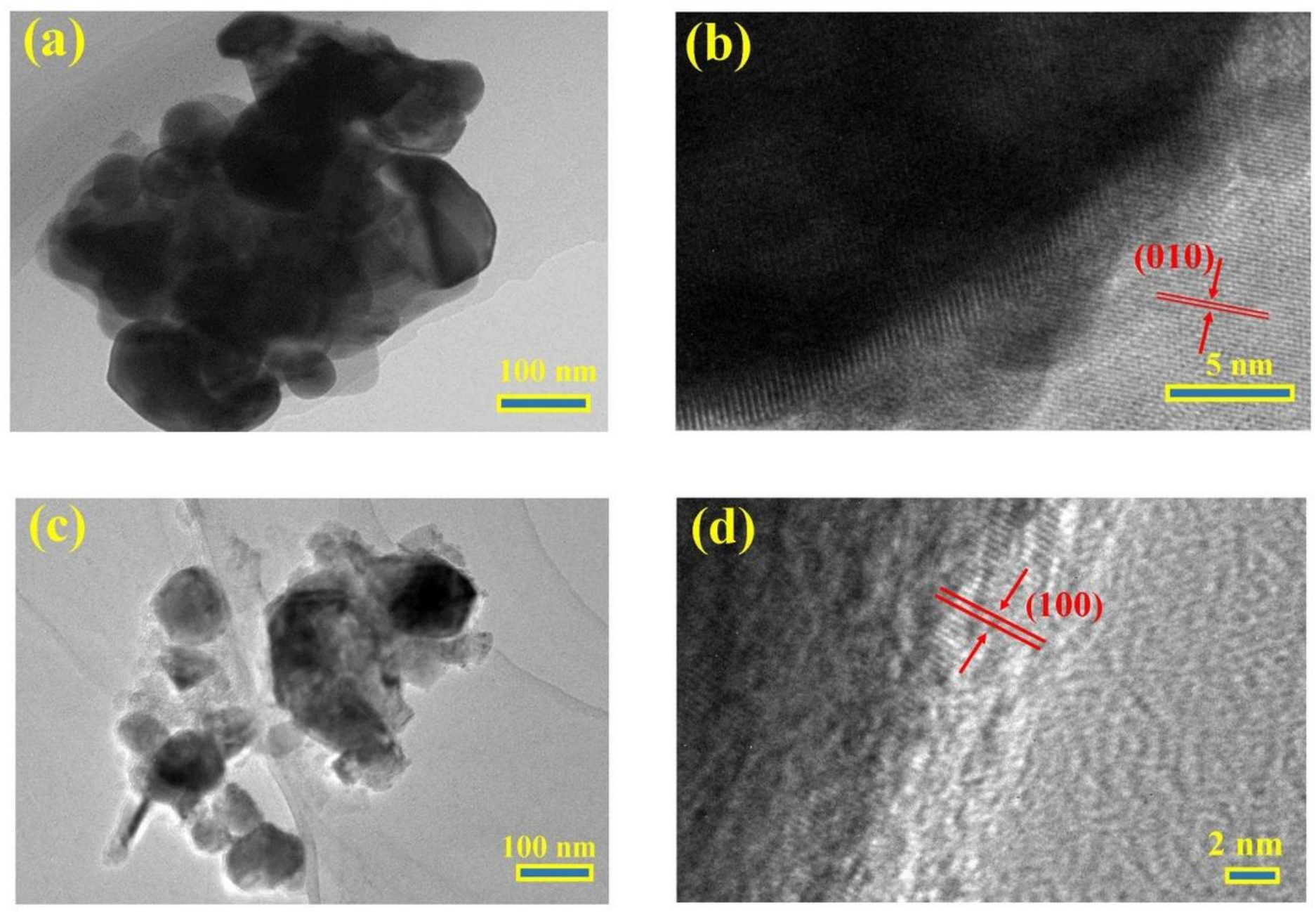

\section{Figure 4}

Please see the Manuscript PDF file for the complete figure caption 


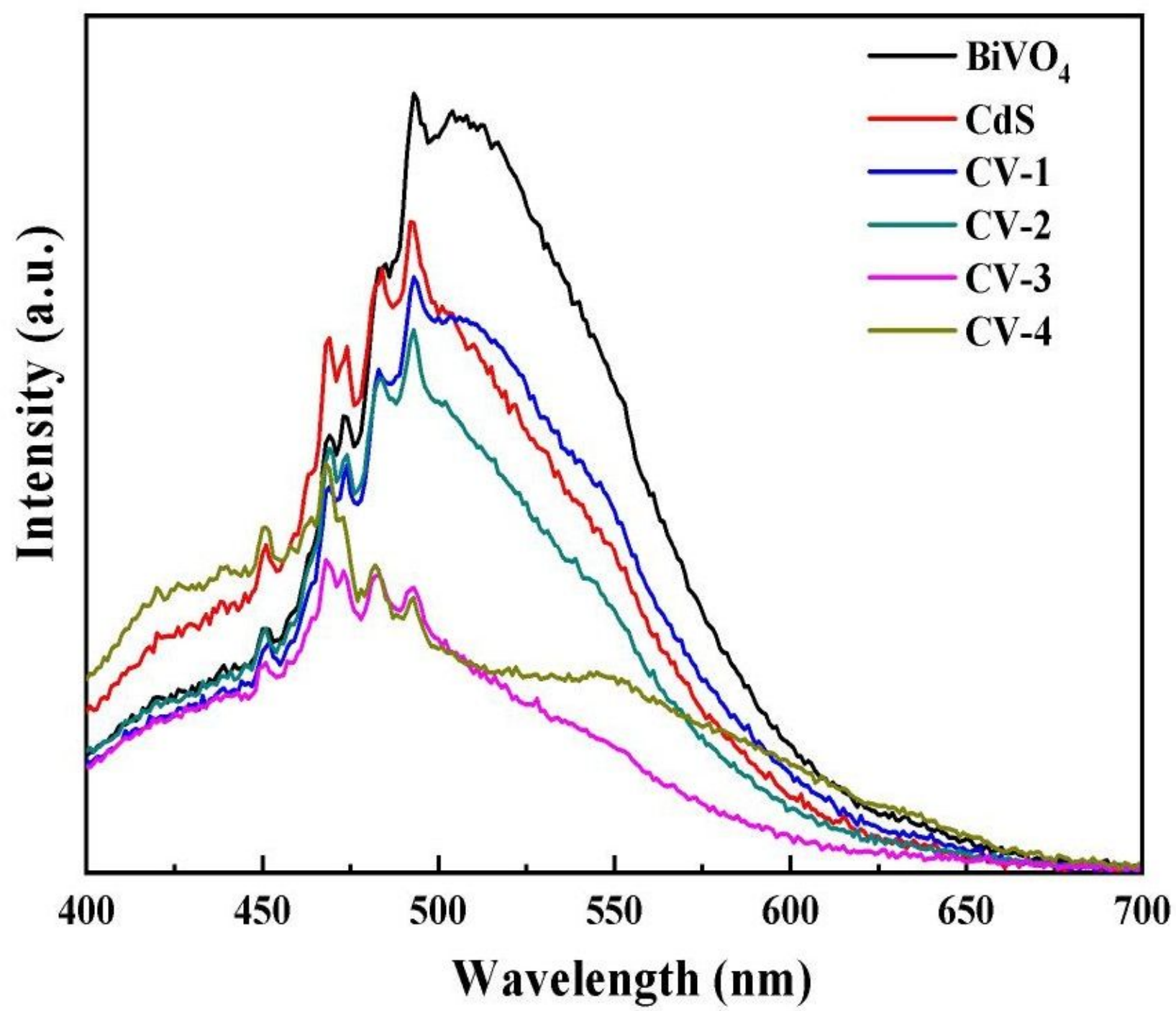

Figure 5

Please see the Manuscript PDF file for the complete figure caption 

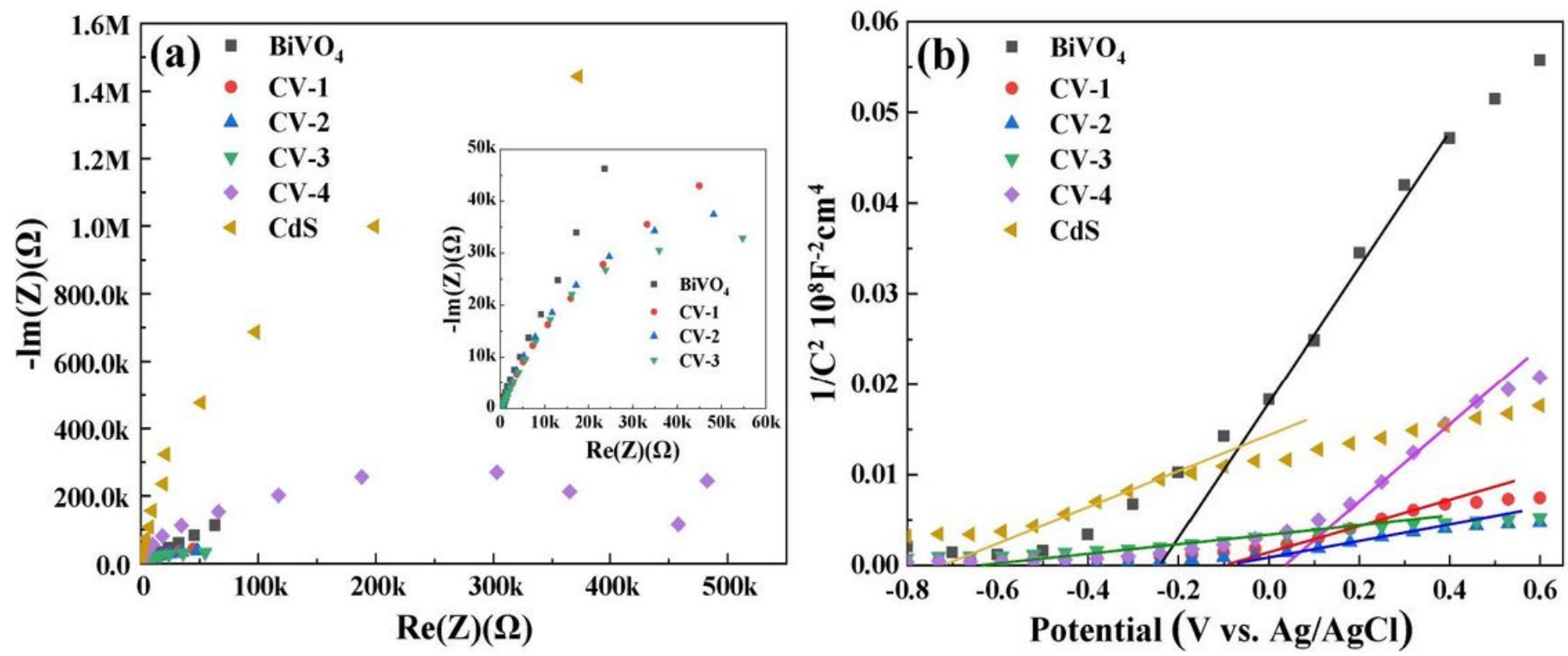

Figure 6

(a) The EIS spectra of samples. (b) The M-S spectra of samples.
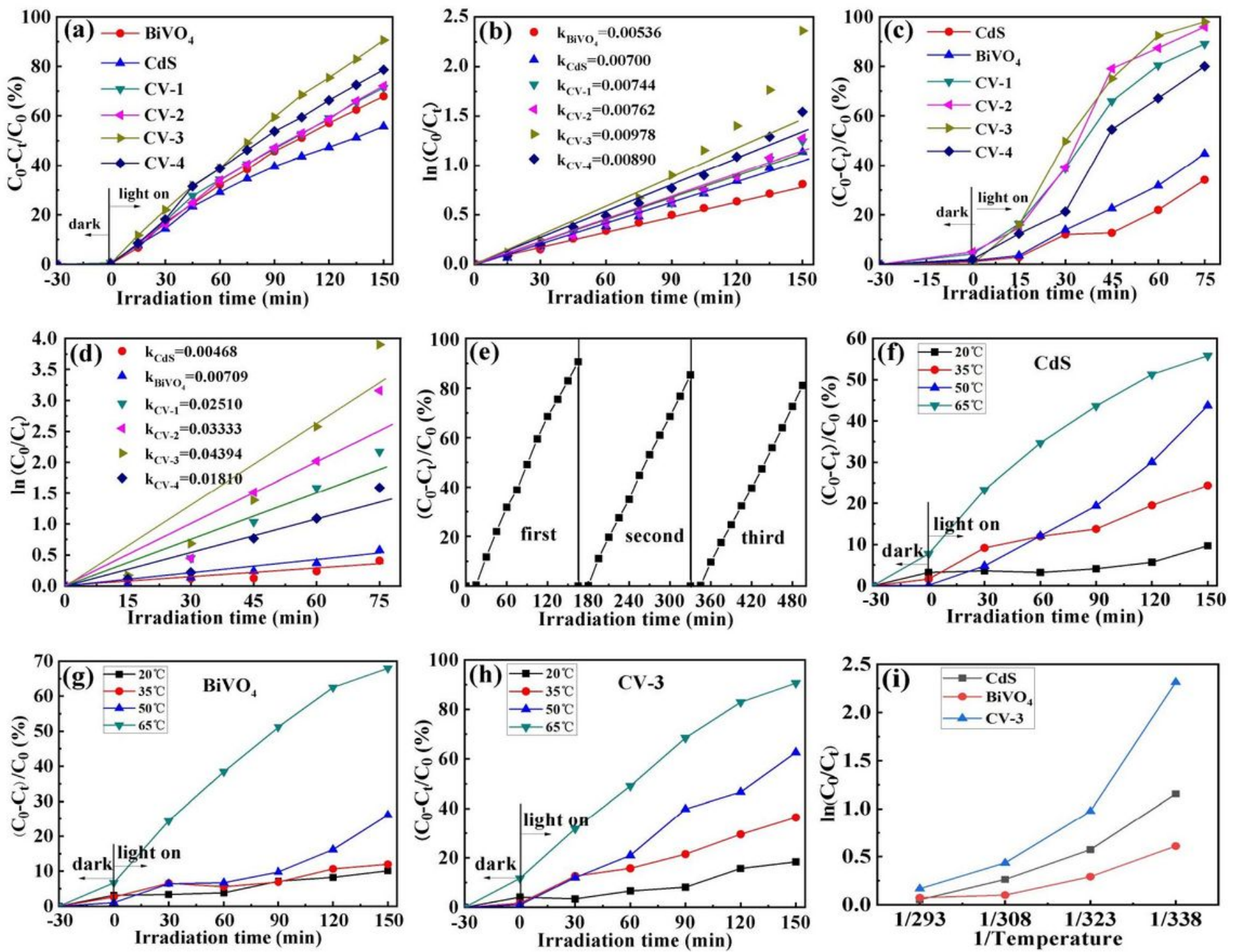
Figure 7

Please see the Manuscript PDF file for the complete figure caption
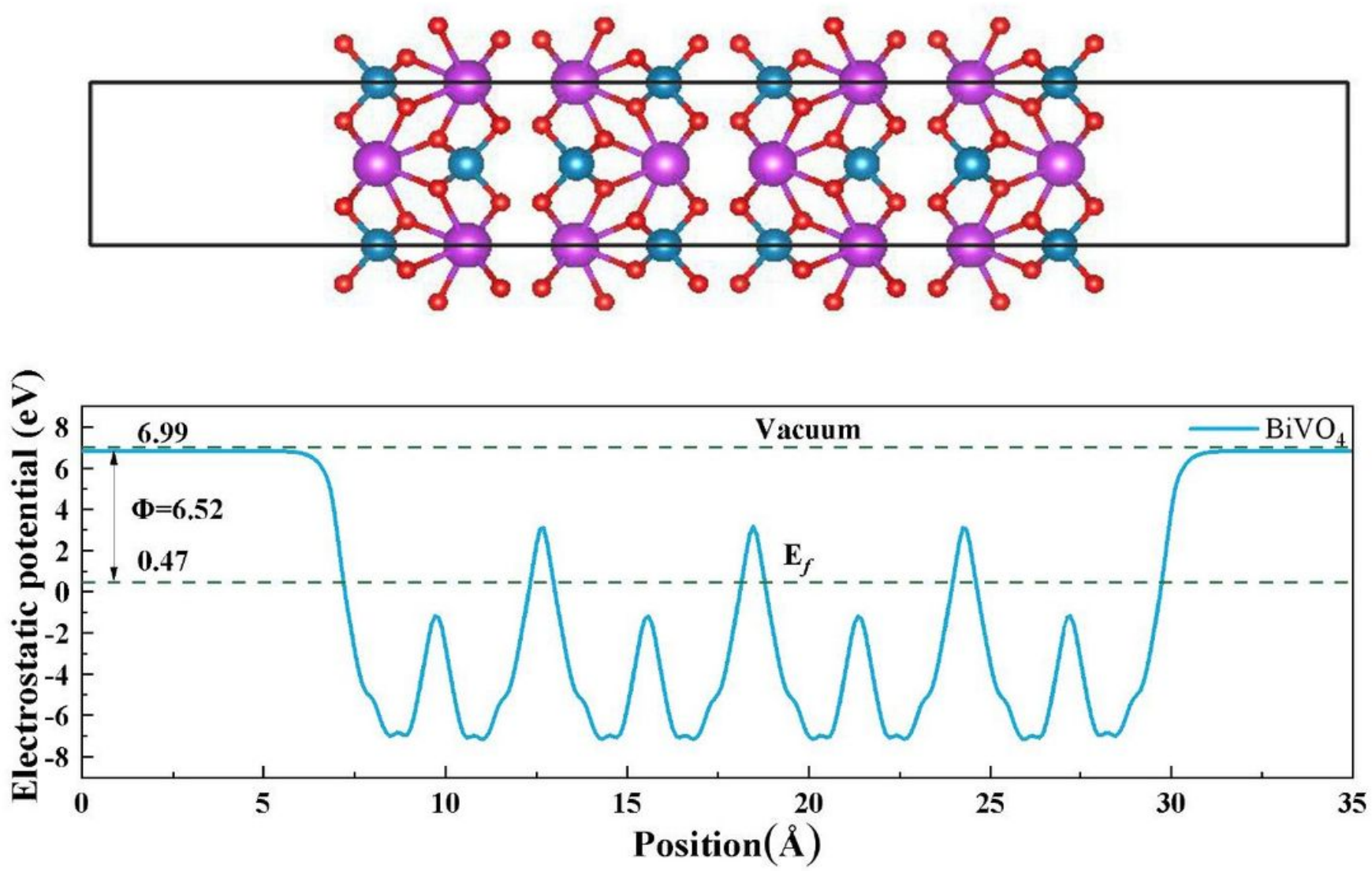

Figure 8

Please see the Manuscript PDF file for the complete figure caption 

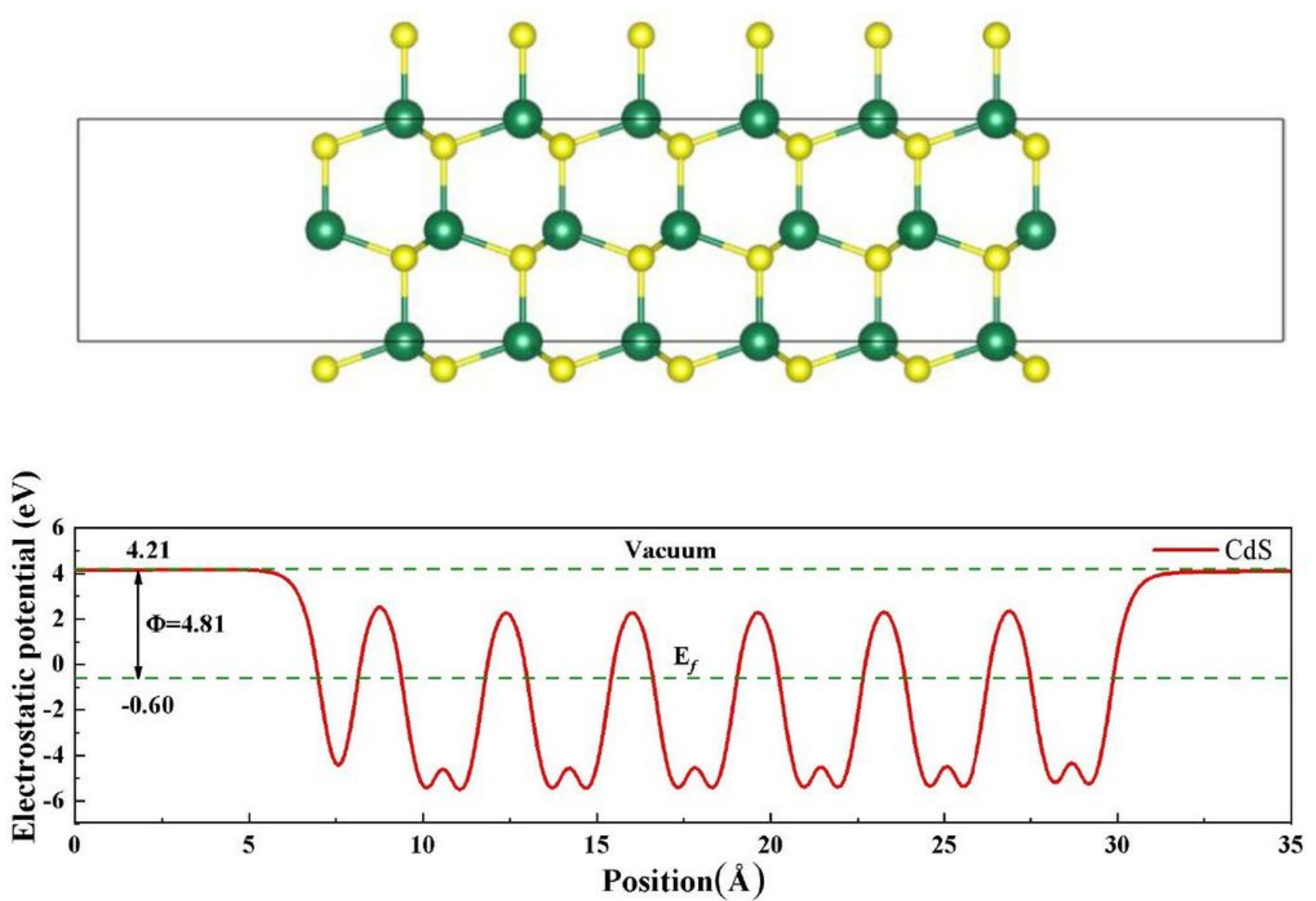

Figure 9

Please see the Manuscript PDF file for the complete figure caption

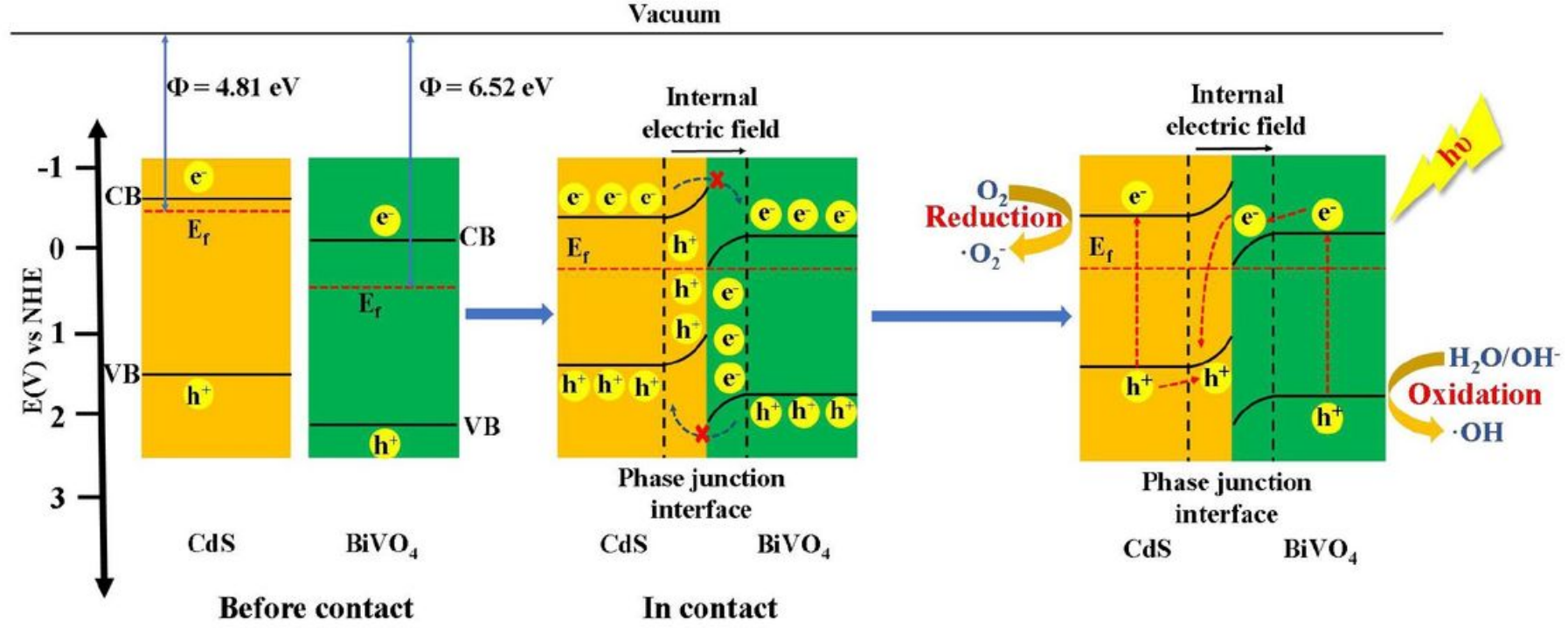

Figure 10

Please see the Manuscript PDF file for the complete figure caption 